\title{
SMART CONTRACTS. REFLEXIONES SOBRE SU CONCEPTO, NATURALEZA Y PROBLEMÁTICA EN EL DERECHO CONTRACTUAL
}

\author{
SMART CONTRACTS. REFLECTIONS ON ITS CONCEPT, \\ NATURE AND PROBLEMS IN CONTRACT LAW
}

\author{
Aitor Mora Astaburuaga ${ }^{1}$ \\ Investigador predoctoral en formación FPI-UR/CAR 2020 \\ Universidad de La Rioja
}

Sumario: I. Introducción; II. El concepto de smart contract; III. Naturaleza jurídica de los Smart contracts: ¿Son realmente contratos?; III.A. Smart contract como documento; III.B. Smart contract como herramienta de ejecución del contrato; III.C. El concepto de "contrato legal inteligente" (smart legal contract); III.C.1). "Contrato legal inteligente" como nueva categoría contractual; III.C.2). Los smart legal contracts como contratos de venta automática; IV. Problemática; IV.A. Cuestiones sobre ley y jurisdicción aplicable; IV.B. Cuestiones relativas a la formación del contrato; IV.B.1). Identificación y capacidad de las partes; IV.B.2). Vicios en el consentimiento; IV.B.3). Discrepancias entre el acuerdo y el código; $V$. Buenas prácticas para la integración de smart contracts en las relaciones jurídicas; VI. Conclusiones.

Resumen: La figura del smart contract fue concebida a finales del siglo pasado, sin embargo, ha ido pasando desapercibida todos estos años hasta el desarrollo de la tecnología de la cadena de blo-

1 Este trabajo ha sido realizado en relación con las actividades realizadas en el Proyecto I+D+I DER2017-84748-R, Mercado único digital europeo y protección de los consumidores: perfilando los derechos de las partes en contratos de sumininistro de contenidos digitales; IP. Sergio Cámara Lapuente. 
ques (o blockchain) y, en especial, hasta el "boom" de las criptomonedas de finales de 2017. El desarrollo de aplicaciones de esta tecnología está incrementando y resulta necesario realizar un análisis de las consecuencias jurídicas que tiene su uso. De este modo, mediante este trabajo se trata de abordar su concepto, su naturaleza jurídica y se pretende analizar algunos de los posibles problemas jurídicos derivados de su uso para así poder dar con algunas soluciones que hagan viable su estandarización en el Derecho contractual.

Palabras clave: Contrato inteligente; contrato legal inteligente; cadena de bloques; bitcoin; contratación electrónica.

Abstract: The institution of the smart contract was conceived at the end of the last century. However, it has been going unnoticed all these years until the development of the technology of blockchain and, in particular, to the "boom» of cryptocurrencies of the late 2017. The development of applications of this technology is increasing and it is necessary to carry out an analysis of the legal consequences of its use. This work seeks to address its concept, its legal nature and seeks to analyses some of the possible legal problems arising from its use in order to be able to find some solutions that make its standardisation in contract law viable.

Keywords: smart contract; smart legal contract; blockchain; bitcoin; e-contract.

\section{INTRODUCCIÓN.}

La temática que se ha escogido este año para los Premios García Goyena es: "Soluciones jurídicas ante los retos de la innovación". Un tema tan amplio como complicado e interesante.

Nos encontramos en un momento en que la tecnología avanza a pasos agigantados y tiene un papel fundamental en nuestras vidas hasta el punto de que se considera que nos encontramos dentro de una cuarta revolución industrial ${ }^{1}$.

Revolución industrial que persigue la automatización de procesos, para lo que se emplean tecnologías como la inteligencia artificial (IA), el internet de las cosas (IoT en sus siglas inglesas), el cloud computing (o almacenamiento en la nube) y blockchain (o en

1 SCHWAB, K., La cuarta revolución industrial, Debate, 2016; PERASSO, V., "Qué es la cuarta revolución industrial (y por qué debería preocuparnos)", BBC Mundo, 2016 (http://www.bbc.com/mundo/noticias-37631834). 
español, cadena de bloques, la tecnología que sustenta el afamado bitcoin) -entre otras-. Todas estas tecnologías, aunque existen desde hace años (la mayoría desde el siglo pasado), se encuentran en fase de desarrollo y nos ofrecen múltiples oportunidades de innovación.

Sin embargo, si hay un concepto tecnológico representativo de esta cuarta revolución industrial es el smart contract. Si bien fue concebido a finales del siglo pasado ${ }^{2}$, se ha popularizado a raíz de la difusión de blockchain (en mayor medida desde 2014 cuando se creó la blockchain de Ethereum ${ }^{3}$ ).

Vemos cómo empresas y Estados están invirtiendo en aplicaciones prácticas de estas tecnologías ${ }^{4}$. Constantemente hay noticias sobre empresas que se han lanzado al desarrollo de soluciones basadas en smart contracts ${ }^{5}$, destacando el trabajo que están llevando a cabo las de los sectores asegurador (insurtech) y financiero (fintech). Los productos con base en esta tecnología aún son sencillos ${ }^{6}$, aunque es previsible que se utilizarán para gestionar relaciones jurídicas cada vez más complejas.

El impulso técnico de esta tecnología y el aumento de empresas desarrollando soluciones basadas en smart contracts ha supuesto que se empiece a analizar este concepto desde el sector jurídico. De hecho, vemos cómo se han abierto distintos debates en torno a esta figura dentro del ámbito jurídico. Algunos más triviales como preguntarse si van a suponer la desaparición de algunos profesionales

2 A pesar de que Nick Szabo escribió sobre ellos antes, se puede considerar que el artículo que dio comienzo a todo es SZABO, N., The Idea of Smart Contracts, 1997 (disponible en: http://www.fon.hum.uva.nl/rob/Courses/InformationInSpeech/ CDROM/Literature/LOTwinterschool2006/szabo.best.vwh.net/idea.html).

3 Ethereum es una red blockchain concebida especialmente para la creación de smart contracts y aplicaciones descentralizadas. Vid. BUTERIN, V., Ethereum whitepaper. A next generation smart contract \& decentralized application platform, 2014 (http://www.the-blockchain.com/docs/Ethereum_white_paper-a_next_generation_ smart_contract_and_decentralized_application_platform-vitalik-buterin.pdf).

4 Por ejemplo, el despacho Herbert Smith Freehills, IBM y Data61 han creado un consorcio para poner en marcha una distributed ledger nacional para Australia con el fin de crear una plataforma fiable para que los empresarios hagan uso de la tecnología de los Smart contracts (vid. "HSF + IBM Build Australian National Blockchain for Smart Contracts", en Artificial Lawer, https://www.artificiallawyer. com/2018/08/29/hsf-ibm-build-australian-national-blockchain-for-smart-contracts/).

5 Entre muchos otros, es interesante el proyecto Change the block, una plataforma de smart contracts para despachos de abogados, creada con el asesoramiento del despacho Pinsent Masosns y destinataria de subvenciones dentro del programa de la UE Horizonte 2020 (https://www.changetheblock.com/).

6 Como ejemplo, podemos ver cómo la compañía aseguradora AXA ha lanzado un nuevo seguro que cubre el retraso en los vuelos (https://fizzy.axa/). 
del derecho ${ }^{7}$ o si los abogados van a necesitar aprender programación ${ }^{8}$; hasta otros jurídicamente más relevantes como si realmente son contratos o no ${ }^{9}$ (siendo éste uno de los puntos clave que se va a abordar mediante este trabajo).

Si a todo esto unimos que los Tribunales todavía no han tenido ocasión de pronunciarse sobre la naturaleza contractual de esta figura ${ }^{10}$; que los trabajos doctrinales que la estudian de forma pormenorizada son aún escasos (sobre todo conforme a nuestro ordenamiento jurídico); y que hay un gran interés por parte de la Unión Europea en el estudio de esta tecnología ${ }^{11}$ no cabe duda de que merece la pena pararse a estudiar la figura del smart contract desde un punto de vista jurídico.

\section{EL CONCEPTO DE SMART CONTRACT.}

No existe realmente un consenso sobre lo que es o no es un smart contract (o, en su traducción al español, "contrato inteligente") y, por tanto, es imposible que exista un concepto universal del mismo ${ }^{12}$.

Encontramos a quienes los denominan "máquinas autónomas"13; a quienes consideran que son "secuencias de código y datos que se

7 COLOMBO, C., ¿Un mundo sin abogados? Siglo XXI: smart contracts, LinkedIn, 2017 (https://es.linkedin.com/pulse/un-mundo-sin-abogados-siglo-xxi-smartcontracts-camila-colombo).

8 PASCUAL, M. G., "Si quieres ser jurista, aprende a programar", $R e$ tina. El País, 2018 (https://retina.elpais.com/retina/2018/01/26/tendencias/1516984111_539811.html).

9 Resuena en las redes, por un lado, la máxima "ni son contratos ni son inteligentes", mientras que por otro encontramos a aquellos que sostienen que son contratos en sí mismos. Vid. PLAZA LÓPEZ, J. A., "Los "smart contracts" no son tan perfectos como nos han vendido", Retina. El País, 2018 (https://retina.elpais.com/retina/2018/03/05/tendencias/1520249835_156767.html).

10 Si bien, sí que se empiezan a ver pronunciamientos respecto de su carácter probatorio, por ejemplo (vid. el caso de China, ORTEGA, A.; PUERTAS, O., "Blockchain, admitido como medio de prueba en juicio en China”, en Blog Cuatrecasas, 16.7.2018 (https://blog.cuatrecasas.com/propiedadintelectual/blockchain-prueba-juicio-china/).

11 Véanse, por ejemplo, los trabajos realizados por The European Union Blockchain Observatory and Forum (https://www.eublockchainforum.eu/reports).

12 ORCUTT, M., "La receta del caos: regular los contratos inteligentes sin saber qué son", en MIT Technology Review, 6.6.2018 (https://www.technologyreview. es/s/10117/la-receta-del-caos-regularlos-contratos-inteligentes-sin-saber-que-son).

13 VOLPICELLI, G., "Smart contracts sound boring but they're more disruptive than bitcoin", en Motherboard, 16.2.2015 (https://motherboard.vice.com/en_us/article/pgaxjz/smart-contracts-soundboring-but-theyre-more-disruptive-than-bitcoin;). 
almacenan en una determinada dirección de la cadena de bloques"14; a los que sostienen que son contratos que se autoejecutan ${ }^{15}$, etc. De este modo, es imprescindible comenzar tratando el concepto de esta figura desde sus orígenes.

La idea que subyace a los smart contracts es permitir que las cláusulas contractuales puedan ser integradas en aparatos electrónicos o programas informáticos, de modo que se consiga un sistema de contratación que dificulte el incumplimiento contractual y eleve las consecuencias nocivas del mismo para el incumplidor ${ }^{16}$ desincentivándolo.

Su finalidad es agilizar y asegurar las relaciones contractuales, de modo que no sea necesario confiar en la otra parte porque hay un programa informático que garantiza que el contrato se va a cumplir. A su vez, esto permite evitar acudir a los tribunales para instar el cumplimiento contractual, de modo que "obedece a la idea de autoprotección contractual del ciudadano, y busca alternativas a la administración de justicia" (ROSALES DE SALAMANCA RODRÍGUEZ) ${ }^{17}$.

Esto se consigue con la plasmación de ciertas condiciones contractuales en un lenguaje que pueda ser comprendido e interpretado

14 TUR FAÚNDEZ, C., Smart contracts. Análisis jurídico, REUS, Madrid 2018, pág. 51.

15 WERBACH, K; CORNELL, N., "Contracts ex machina", en Duke Law Journal, núm. 67, marzo 2017 (https://scholarship.law.duke.edu/cgi/viewcontent. cgi? article $=3913$ \&context=dlj): "smart contract as an agreement in digital form that is self-executing and self-enforcing".

16 SZABO, N., Smart Contracts..., op. cit. Se analiza de forma pormenorizada el concepto de smart contract que da SZABO en GONZÁLEZ-MENESES, M., "Smart contracts: ¿hacia una economía sin derecho contractual?”, en Aranzadi digital, núm. $1 / 2020$.

17 ROSALES DE SALAMANCA RODRÍGUEZ, F., Qué es un Smart contract para un notario en https://www.notariofranciscorosales.com/smart-contract-y-lamaquina-de-pinball/, 9.7.2018 (). En este sentido, también SALVADOR CODERCH, P., "Contratos inteligentes y Derecho de contratos", en InDret, 3/2018 y MORA ASTABURUAGA, A., “¿Para qué sirven los Contratos Inteligentes? Smart contracts como herramienta de cambio", en Legal Today, 16.1.2019 (http://www.legaltoday. com/firmas/legaltech/para-que-sirven-los-contratos-inteligentes-smart-contractscomo-herramienta-de-cambio). De hecho, hay quienes sostienen firmemente que "(s)i un contrato depende de la justicia para asegurar su cumplimiento, o necesita cumplir con la legislación vigente, no tiene mucho sentido implementarlo como contrato inteligente. Y si no, no tiene sentido analizarlo desde la óptica del derecho ni necesita de juristas" (FISCALIDADBTC, "Los contratos inteligentes y el Derecho", en https://medium.com/@fiscalidadbtc/los-contratos-inteligentes-y-elderecho-c5ef82b1641, 11.7.2018). 
por un ordenador, de modo que éste pueda ejecutar dichas órdenes por sí mismo ${ }^{18}$.

Por tanto, podemos considerar smart contract a los "scripts o pequeños programas, cuyo efecto sea que, una vez concluido (un) acuerdo y señalados uno o varios eventos desencadenantes, la producción de los eventos programados conllev(e) la ejecución automática del resto del contrato, sin que quepa modificación, bloqueo o inejecución de la prestación debida" (PRENAFETA RODRÍGUEZ) ${ }^{19}$.

En esta línea, los smart contracts se han configurado como "secuencias de instrucciones o indicaciones destinadas a ser utilizadas, directa o indirectamente, en un sistema informático para realizar una o varias prestaciones de un contrato (por tanto, programas de ordenador), con la particularidad de que, una vez activadas, las partes dejan de tener el control de su cumplimiento, que se realizará por sí mismo" (ECHEBARRIA SÁENZ) ${ }^{20}$.

De estas definiciones podemos extraer las características esenciales de los smart contracts:

1. Son "programas informáticos". Su estructura está basada en un sistema de reglas lógicas (función booleana: si pasa esto, entonces pasa aquello ${ }^{21}$ ) y, por tanto, en una estructura condicional ${ }^{22}$.

2. Están destinados a ejecutar prestaciones de un contrato a partir de una secuencia de instrucciones programadas y, por tanto, para la producción de efectos jurídicos.

3. Tienen la capacidad de "autoejecutarse" una vez están activados. Cuando el "contrato inteligente" detecte el cumplimiento de las condiciones establecidas en el código informático, ejecutará automáticamente el contrato.

18 SZABO, N., A formal language for analyzing contracts, 2002 (Disponible en: http://www.fon.hum.uva.nl/rob/Courses/InformationInSpeech/CDROM/Literature/ LOTwinterschool2006/szabo.best.vwh.net/contractlanguage.html).

19 PRENAFETA RODRÍGUEZ, J., "Smart contracts: aproximación al concepto y problemática legal básica”, en Diario La Ley, núm. 8824, 15.11.2016 (LA LEY 6489/2016).

20 ECHEBARRÍA SAÉNZ, M., "Contratos electrónicos autoejecutables (smart contracts) y pagos con tecnología blockchain", en Revista de estudios europeos, núm. 70, julio-diciembre 2017.

21 En lenguaje informático se conoce esta lógica como "función If-Else".

22 Jurídicamente podemos hablar de obligaciones condicionales (vid. Arts. 1113 a $1123 \mathrm{CC})$. 
Además, si bien no siempre se cumple, se busca su irrevocabilidad (una vez aceptadas las condiciones las partes dejan de tener el control sobre las mismas, no pudiendo modificar, bloquear o inejecutar el contrato). Entre otras $\operatorname{cosas}^{23}$, es la búsqueda de esta irrevocabilidad lo que ha hecho de blockchain el entorno de desarrollo de "contratos inteligentes" por excelencia, ya que permite evitar que cualquiera de las partes pueda interferir en el proceso de ejecución de las condiciones pactadas. Esto ha supuesto que muchos autores, e incluso Estados que comienzan a legislar sobre esta materia ${ }^{24}$, insertan el funcionamiento de smart contracts sobre la cadena de bloques como elemento esencial de estos "contratos", sin embargo, esto no significa que no se puedan desarrollar fuera de este entorno. De hecho, como apunta el propio autor de este concepto, la máquina de vending es el smart contract más primitivo ${ }^{25}$, y encontramos múltiples ejemplos más elaborados sobre tecnologías que pueden ser consideradas smart contracts anteriores a la existencia del propio blockchain ${ }^{26}$.

23 Blockchain resuelve en gran medida los principales problemas con los que contaban los smart contracts y por los que su desarrollo había sido limitado a pesar de que fueran concebidos hace más de 20 años: (1) la dificultad del código informático para afectar a activos reales. Con la llamada "tokenización de activos" se ha permitido representar de forma digital (y, por tanto, mediante código informático) bienes físicos de un modo fehaciente. Por tanto, con esta tecnología podemos programar mediante código informático las transacciones de cualquier activo, ya que se pueden representar digitalmente de forma inconfundible; y (2) la extensa regulación y control sobre el dinero. Con la creación de los tokens se eliminan los problemas relativos a la emisión y transmisión de dinero, permitiendo así tener activos globales cuyas transmisiones se pueden programar sin necesidad de que actúen intermediarios en la relación. En este sentido, véase: MORELL RAMOS, J., "Cómo crear un smart contract mediante términos y condiciones", en https://terminosycondiciones.es/2016/09/21/como-crear-smart-contract-mediante-terminos-condiciones/.

24 Para un análisis actual del desarrollo normativo sobre este tipo de instrumentos contractuales vid. ARGELICH COMELLES, C., "Smart contracts o Code is Law: soluciones legales para la robotización contractual”, en InDret, 2/2020.

${ }_{25}$ SZABO, N., Smart Contracts: Building Blocks for Digital Markets, 1996 (http://www.fon.hum.uva.nl/rob/Courses/InformationInSpeech/CDROM/Literature/ LOTwinterschool200 6/szabo.best.vwh.net/smart_contracts_2.html).

26 Vemos ejemplos como los DRM (Digital rights management, sistemas de gestión de derechos digitales que permiten el control del uso de los contenidos digitales mediante la inserción de un código informático, que van desde una simple indicación de los usos permitidos del contenido -los Creative Commons-, hasta restricciones tales que te impiden compartirlo o incluso reproducirlo en determinados dispositivos -Kindle-); el Via-T (una vez que se contrata el sistema de telepeaje se le da al usuario un dispositivo asociado a su cuenta bancaria; este dispositivo emite una señal que es recibida por una antena cuando pasa por una vía de peaje dotada de Vía$\mathrm{T}$ y se levanta la barrera permitiendo el paso o salida de la autopista y anotando los puntos tanto de entrada como de salida para efectuar el cobro correspondiente al trayecto realizado automáticamente); o los sistemas de alquiler de vehículos como Car2Go (https://www.car2go.com/ES/es/), entre otros muchos.

(C) UNED. Revista de Derecho UNED, núm. 27, 2021 
Por tanto, de manera resumida, se podría decir que los smart contracts son secuencias de código informático destinadas a ejecutar prestaciones de un contrato de manera automática una vez que se cumplan una serie de circunstancias previstas por las partes.

\section{NATURALEZA JURÍDICA DE LOS SMART CONTRACTS: ¿SON REALMENTE CONTRATOS?}

En multitud de $\operatorname{artículos}^{27}$ relativos a esta figura ni siquiera se plantea esta cuestión, se da por sentado que sí son contratos o se dice que en sede de Derecho contractual existe libertad de forma (arts. $1278 \mathrm{CC}$ y $51 \mathrm{Ccom}$ ) y, por tanto, un código informático puede ser perfectamente un contrato siempre que cumpla con las exigencias de los arts. 1261 y ss. CC (existencia de consentimiento válido de las partes, objeto lícito y causa).

Sin embargo, decir esto no aporta nada. Es obvio que si se cumplen los requisitos del contrato estaremos ante uno y si no, no; con independencia de la figura que se analice. Lo que no es tan obvio es si los smart contracts realmente cumplen en la práctica con estos requisitos.

\section{III.A. Smart contract como documento.}

El concepto de contrato se ha configurado en nuestro ordenamiento a partir de tres preceptos del Código Civil, los arts. 1089, 1091 y 1254 , de modo que actualmente entendemos como contrato al acuerdo bilateral cuyo objeto es crear, modificar o extinguir una relación jurídica que vincula a las partes contratantes a cumplir con una o varias obligaciones determinadas ${ }^{28}$.

27 Véanse como ejemplos de esto: GÓRRIZ LÓPEZ, C., “Tecnología blockchain y contratos inteligentes", en NAVAS NAVARRO, S. (Dir.), Inteligencia artificial, Tirant lo blanch, Valencia, 2018, pág. 192; BOURQUE, S., FUNG LING TSUI, S., "A lawyer's introduction to smart contracts", en Scientia Nobilitar Reviewed legal studies, 2014, pág.10; ECHEVARRÍA, M., op. cit; pág. 72.

28 CARRASCO PERERA, A. (Dir.), CORDERO LOBATO, E. y MARÍN LÓPEZ, M.J., Lecciones de Derecho Civil. Derecho de obligaciones y contratos en general, 2. ${ }^{a}$ ed., Tecnos, Madrid, 2016, pág. 15. En este sentido también: MARTÍNEZ DE AGUIRRE ALDAZ, C. (Coord.), Curso de Derecho civil II. Volumen I. Teoría general de la obligación u el contrato, 5. ${ }^{a}$ ed. Edisofer, Madrid, 2018; DÍEZ-PICAZO, L. y GULLÓN, A., Sistema de Derecho Civil. Volumen II. El contrato en general. La relación obligatoria, 11. ${ }^{a}$ ed., Tecnos, Madrid, 2016, pág. 19. Además, véase también la clásica definición de Díez Picazo según la cual un contrato es "un acuerdo de voluntades de dos o más personas dirigido a crear obligaciones entre ellas" en DÍEZ-PI- 
El contrato, por tanto, es el acuerdo de voluntades al que han llegado las partes en sí mismo y nace "por el mero consentimiento" (art. $1258 \mathrm{CC}$ ), esto es, con la concurrencia de oferta y aceptación (art. $1262 \mathrm{CC}$ ).

Esto, junto a lo dispuesto en el art. 1278 CC (libertad de forma), conforma el principio espiritualista que rige en los sistemas de Derecho continental. No importa la forma en que se plasme el acuerdo ${ }^{29}$. La existencia del contrato se fundamenta en el acuerdo de volunta$\operatorname{des}^{30}$. Así, en función de este principio que rige nuestro derecho contractual, no debemos confundir el contrato (el acuerdo al que han llegado las partes) con el documento que lo soporta (en el caso de los smart contracts, el código informático).

Esta diferencia entre el contrato y el documento se plasma en dos aspectos fundamentales:

1. La necesidad de integración que aparece en los arts. 1.255 y $1.258 \mathrm{CC}$ cuando se establece que los contratos obligan no solo a lo pactado por las partes, "sino también a todas las consecuencias que, según su naturaleza, sean conformes a la buena fe, al uso y a la ley".

2. La necesidad de interpretación del contenido del contrato teniendo en cuenta la verdadera intención de las partes más allá de lo documentado (art. 1281.II CC) ${ }^{31}$.

De este modo, el documento tendrá carácter dispositivo en el sentido de que «incorpora una declaración jurídica constitutiva, un acto de voluntad jurídico-negocial o de otra clase (ley, sentencia, mandato de autoridad en general, o el negocio jurídicoprivado, unilate-

CAZO Y PONCE DE LEÓN, L., Fundamentos de Derecho civil patrimonial, vol. I, $6^{\mathrm{a}}$ ed., Thomson-Civitas, Cizur Menor, 2009.

29 Exceptuando, obviamente, los contratos formales.

30 CARRASCO PERERA, A. (Dir.), op. cit., pág. 141.

31 Es importante tener en cuenta la naturaleza internacional que tiene esta figura, por tanto, no debemos olvidar la gran preponderancia del sistema jurídico inglés en el ámbito internacional y sus grandes diferencias (especialmente en materia contractual) con los sistemas de Derecho continental. En ámbito de Derecho contractual inglés, en principio, lo que no está plasmado en el contrato escrito no existe, se rige por el principio de la santidad del contrato (aunque existen algunas excepciones que permiten la integración del contrato fundamentadas en que si no se integrara el contrato carecería de sentido comercial: la teoría de los términos implícitos -implied terms-; y el officious bystander test (vid. CARTWRIGHT, J., "Una introducción al Derecho de Contratos Inglés", en HORNERO MÉNDEZ, C. (Dir.), Derecho de contratos: nuevos escenarios y nuevas propuestas, Thomson Reuters Aranzadi, Cizur Menor, 2016)). 
ral o bilateral: testamento, contrato, etc.)"32 (GÓMEZ ORBANEJA) y servirá como medio para facilitar la prueba de la existencia de una relación jurídica ${ }^{33}$ (es más fácil probar que existe un negocio jurídico si se plasma en papel y las partes lo firman que si llegan a un acuerdo oral).

De este modo, se da por supuesto, en principio, que lo contemplado en el documento conforma la verdadera intención de las partes; si bien no siempre se va a corresponder con la realidad negocial, ya sea porque lo plasmado en el documento esté incompleto (para lo que será necesaria la integración), no sea claro (para lo que será necesaria la interpretación), o porque lo plasmado en el documento no se corresponda con la verdadera voluntad de las partes (véanse, p.e., la existencia de vicios en el consentimiento, o la existencia de contratos simulados) $)^{34}$.

Por tanto, la primera función que tiene un smart contract es la de plasmar el contenido de la relación contractual en lenguaje informático, en código, lo que no afecta realmente a la naturaleza jurídica del contrato. Así como no afecta a la naturaleza jurídica que el acuerdo se plasme en un idioma u otro, tampoco importará que la fijación se realice en un lenguaje de programación.

\section{III.B. Smart contract como herramienta de ejecución del contrato.}

A su vez, a pesar de que el smart contract sea el documento que plasma el acuerdo de las partes y no pueda ser considerado como contrato, es necesario constatar que su papel en la relación va más allá. No es un simple elemento estático que plasma los acuerdos a

32 GÓMEZ ORBANEJA, E., Derecho Procesal Civil, vol.1º, Madrid, 1976, págs. 341. En este sentido también MORENO NAVARRETE, M.A., en La prueba documental. Estudio Histórico-Jurídico y Dogmático, Marcial Pons Barcelona, 2001, pág. 20, cuando dice que "(e)l documento jurídico es el signo visible de la declaración de voluntad misma (...) es la forma exterior del negocio". También se comparte este concepto en GÓMEZ COLOMER, J.L., "Lección undécima. La prueba: los medios de prueba en concreto (III)", en MONTERO AROCA, J., GÓMEZ COLOMER, J.L., BARONA VILAR, S., CALDERÓN CUADRADO, M.P., Derecho jurisdiccional II. Proceso civil, 23. ${ }^{\text {a }}$ ed., Tirant lo blanch, Valencia, 2015, pág. 264.

33 PICÓ I JUNOY, J., ABEL LLUCH, X., La prueba documental, J.M. Bosch Editor, Barcelona, 2010, págs. 41-44.

34 PARRA LUCÁN, M.A., "Interpretación e integración de los contratos" en MARTÍNEZ DE ALDAZ, C. (coord.), Curso de Derecho civil II. Volumen I. Teoría general de la obligación y el contrato, 5. ${ }^{a}$ ed. Edisofer, Madrid, 2018, págs. 437-460. 
los que han llegado las partes, sino que, además, como se ha explicado supra, ejecuta las prestaciones del contrato.

Del concepto de contrato se extraen sus tres notas características ${ }^{35}$ :

1. El contrato es fuente generadora de obligaciones entre las partes (art. 1089 CC).

2. El contrato es la norma que regula y determina la relación contractual (art. $1091 \mathrm{CC}$ ).

3. El contrato es un acuerdo de voluntades, un negocio jurídico, es la relación contractual creada y regulada por sí misma (art. 1254 CC).

Por tanto, el smart contract realizará, en mayor o menor medida, la función de "norma" (más bien instrumento) que regula la relación contractual en cuanto que ejecuta las obligaciones de las partes automáticamente una vez que se cumplan las condiciones pactadas y, por tanto, tendrá una gran incidencia en cuanto a cómo se desarrollará la relación contractual, pero no en cuanto a su naturaleza, ya que el modo de ejecución no incide en la naturaleza del contrato en sí mismo ${ }^{36}$.

Si estamos, por ejemplo, ante un contrato de arrendamiento dará igual que se automatice el acceso a la vivienda alquilada una vez se haya realizado el pago (permitiendo el acceso cuando se acerque un teléfono móvil hasta que expire el tiempo contratado y ya no permita entrar más) ${ }^{37}$, o que al recibir el pago el arrendador sea el encargado de darle la llave al cliente para que este pueda abrir y cuando termine el periodo de estancia contratado le solicite su devolución.

Obviamente, la automatización del cumplimiento obligacional mediante smart contracts podrá tener (y tendrá) ciertas consecuencias jurídicas y, de hecho, plantea varios problemas que se estudiarán infra. Sin embargo, el insertar un código informático dentro de

35 Vid. comentarios al art. 1254 CC en O'CALLAGHAN MUÑOZ, Xavier, en Código Civil comentado y con jurisprudencia, $8^{\text {a }}$ Ed., Wolters Kluwer, Madrid, 2016, y en LÓPEZ Y LÓPEZ, A.M., "Comentario al artículo 1254", en CAÑIZARES LASO, A.; DE PABLO CONTRERAS, P.; ORDUÑA MORENO, J.; VALPUESTA FERNÁNDEZ, R. (Dirs.), Código Civil comentado. Volumen III. Libro IV- De las obligaciones y contratos. Teoría general de la obligación y el contrato (arts. 1088 a 1444), $2^{\mathrm{a}}$ Ed., Aranzadi, Pamplona, 2016, págs. 571 a 574.

36 En este sentido, PREUKSCHAT, A. (Coord.), Blockchain: la revolución indus-

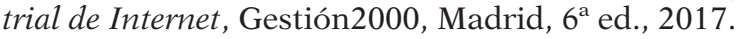

37 Como pasa, a grandes rasgos, en el ejemplo de Slock.it 
una relación contractual para facilitar el cumplimiento de las obligaciones no afectará a la naturaleza contractual.

La naturaleza de los smart contracts es técnica, no jurídica ${ }^{38}$. Son "simples" herramientas que se integran en una relación contractual para facilitar el cumplimiento de las obligaciones a que se hayan vinculado las partes. Por tanto, son una mera "forma de articular un proceso contractual, de facilitar el desarrollo y consumación del contrato, o de las posibles consecuencias que se deriven del incumplimiento de aquel" (FELIU REY) ${ }^{39}$.

De este modo, como herramienta, puede integrarse en cualquier tipo de contrato típico o atípico (compraventa, arrendamiento, depósitos, préstamos, créditos documentarios...), así como también podrá incorporarse a cualquier modalidad de contratación (contratación electrónica, contratos de adhesión, contratos negociados...). Por lo que será a la naturaleza del negocio y a la modalidad de contratación a lo que habrá que atender realmente para delimitar el régimen jurídico aplicable a la relación y no a la forma en que se ejecuta.

\section{III.C. El concepto de "contrato legal inteligente" (smart legal contract).}

\section{III.C.1). "Contrato legal inteligente" como nueva categoría contractual.}

Ante la generalización de la confusión existente en torno al concepto de smart contract, habiendo llegado al punto en que se entiende como cualquier secuencia de código insertada en una red blockchain y, sobre todo, ante la incidencia que va a tener esta figura en cuanto a la regulación de relaciones contractuales, algunos autores han empezado a utilizar el concepto de "contrato legal inteligente" 40 .

38 Podrán ser protegibles, en su caso, por las normas de propiedad intelectual y/o industrial en cuanto que protegen al software como creación.

39 FELIU REY, J., "Smart Contract: Concepto, ecosistema y principales cuestiones de Derecho privado", en La Ley mercantil, núm. 47, 2018. En este sentido también podemos ver WERBACH, K.; CORNELL, N., op. cit.: "Do smart contracts involve promises or obligations? In a significant sense, the answer is "no." The Smart contract sets in motion machinery that the parties cannot subsequently prevent. The fulfillment of the smart contract is not accomplished by some further action by a contracting party, but rather by the completion of this mechanical process".

40 STARK, J., "Making sense of Blockchain Smart Contracts", en Coindesk, 4.6.2016 (https://www.coindesk.com/making-sense-smart-contracts/); TUR FAÚNDEZ, C., op. cit., pág. 59; EU BLOCKCHAIN OBSERVATORY AND FORUM, Legal 
Así, estos se han definido como "contratos celebrados a través de una página web accesible para las partes cuya forma esté constituida por la interfaz de usuario de la aplicación externa y uno o varios programas autoejecutables (smart contracts) residentes en la cadena de bloques con capacidad para interactuar recíprocamente y con dicha interfaz" (TUR FAÚNDEZ) ${ }^{41}$.

Esta definición acota demasiado lo que podrían ser o no los "contratos inteligentes" en la medida en que integra como elementos clave que el software esté desplegado en la cadena de bloques y que el contrato se presente mediante una página web cuando, como se ha visto supra ${ }^{42}$, esto no es necesariamente así. Por tanto, si se eliminan tales elementos de la definición, un "contrato legal inteligente" sería, básicamente, un contrato en el que se ha insertado uno o varios smart contracts como medio de ejecución de las prestaciones.

De este modo, parece que se está tratando de crear una nueva categoría contractual a partir de la integración del concepto de contrato con una herramienta técnica (el smart contract) como elemento diferenciador, por lo que cabría preguntarse si realmente tiene sentido esta diferenciación.

Parece claro, en principio, que no tiene cabida hablar de smart legal contract como un tipo de contrato en el sentido en que hablamos de compraventa, arrendamiento, por ejemplo, ya que la automatización de la ejecución realmente no incide en la naturaleza del negocio jurídico.

Tampoco parece que puedan concebirse como un modelo de formación del contrato ${ }^{43}$ como lo es, por ejemplo, un contrato de adhesión en una página web, ya que cabe que un contrato en el que se integre un smart contract pueda formalizarse de forma escrita, electrónica, verbal, puede ser totalmente negociado o que las condiciones las imponga una de las partes..., las partes son las que deciden el modo en que quieren formalizar su contrato, con independencia de que vaya a existir un smart contract que ejecute las prestaciones del mismo.

and regulatory framework of blockchain and Smart contracts, 27.9.2019, pags. $23 \mathrm{y}$ ss. (https://www.eublockchainforum.eu/reports).

41 TUR FAÚNDEZ, C., op. cit., pág. 60.

42 Véanse los ejemplos del Via-T, los DRM, Car2G que se han mencionado en la nota 27 o, o el de la máquina de venta automático que propuso el propio Nick Szabo.

43 Vid. PARRA LUCÁN, M.A., "La formación del contrato como proceso", en PARRA LUCÁN, M.A. (Dir.), Negociación y perfección de los contratos, Thomson Reuters, Cizur Menor, 2014, págs. 70-82. 
El abanico de posibilidades para integrar un smart contract en el proceso contractual es tan amplio como el ordenamiento mismo. La automatización de la ejecución se puede realizar (teóricamente) en casi cualquier negocio jurídico (si bien habrá que atender a la complejidad que tenga el trasladar las consecuencias del contrato a código informático).

Ahora bien, no es algo nuevo que el legislador cree una nueva categoría contractual basándose en la incidencia de elementos técnicos en los contratos. Un ejemplo claro es la creación del extenso régimen jurídico de la contratación electrónica ${ }^{44}$, cuyo elemento diferenciador es únicamente que el proceso de contratación se celebre "mediante el intercambio de mensajes de datos por medios electrónicos" (DE MIGUEL ASENSIO) ${ }^{45}$.

A su vez, vemos cómo en la Ley de Ordenación del Comercio Minorista (LOCM) se establece un régimen jurídico propio para los "contratos desarrollados por medios automáticos" 46 que se estudiará infra de modo más completo.

Por tanto, aunque no sea necesario ${ }^{47}$, podría resultar útil en esta línea crear una nueva categoría jurídica de "contrato legal inteligente" con el fin de desarrollar un régimen jurídico que establezca de forma clara unas bases para el desarrollo de estos programas informáticos. Así se podría dotar a la relación de una serie de garantías

44 Para constatar las principales normas que son aplicables en esta materia podemos ver en el ámbito internacional la Ley modelo de la CNUDMI sobre comercio electrónico con la guía para su incorporación en el derecho interno de 1996 (entre otras muchas iniciativas tanto públicas como privadas). En el ámbito europeo nos encontramos con la Directiva 2000/31/CE del Parlamento Europeo y del Consejo de 8 de junio de 2000 sobre comercio electrónico. En el ámbito nacional se ha abordado la contratación electrónica mediante la Ley 34/2002, de 11 de julio de servicios de la sociedad de la información y de comercio electrónico, así como también le es aplicable la normativa de consumo (TRLGDCU, en especial arts. 92 y ss.). A su vez, dada la transversalidad de la contratación electrónica le son aplicables multitud de normativas: el Código Civil y el de Comercio; normativa en materia de consumo; normativa sobre firma electrónica; etc.

45 DE MIGUEL ASENSIO, P.A., Derecho privado de internet, $5^{\mathrm{a}}$ ed., Thomson Reuters, Madrid, 2015.

46 MARCO ALCALÁ, L.A., "Contratación al consumo mediante la técnica de vending”, en BERCOVITZ RODRÍGUEZ-CANO, A. (Dir.), Contratos mercantiles, $5^{\mathrm{a}}$ ed., THOMSON REUTERS, Cizur Menor, 2012. El régimen jurídico aplicable a estos contratos lo encontramos en los arts. 49 a 52 LOCM.

47 Una de las características básicas de nuestro ordenamiento es que tiene mecanismos de adaptación (interpretación, analogía...) y, por tanto, con las categorías jurídicas existentes es suficiente para enmarcar legalmente los contratos legales inteligentes (ya se ha dicho que ni la naturaleza jurídica de un contrato ni el modelo de contratación va a cambiar porque se integre un smart contract en la relación). 
técnicas que hagan más segura la contratación en la que se integren estos instrumentos (solventando los problemas que puedan surgir de la aplicación de esta tecnología como los que se estudiarán infra).

Pero hasta que esto ocurra, la única función que tiene el concepto de "contrato legal inteligente" es el de diferenciarlo de los smart contracts entendidos como cualquier secuencia de código integrada en una blockchain, con independencia de su funcionalidad.

III.C.2). Los smart legal contracts como contratos de venta automática.

La venta automática ${ }^{48}$ se configura como "la forma de distribución detallista, en la cual se pone a disposición del consumidor el producto o servicio para que éste lo adquiera mediante el accionamiento de cualquier tipo de mecanismo y previo pago de su importe" (art. 49 LOCM).

Este concepto se aproxima mucho a lo que es un smart legal contract (precisamente porque las máquinas de venta automática son sus precursoras), ahora bien, ¿se les podría aplicar el régimen de la venta automática con carácter general?

El concepto que se establece en el art. 49 pretende ser descriptivo y amplio, de modo que pueda comprender gran variedad de fenómenos de la realidad social. Si bien está clara cuál ha sido la imagen que ha inspirado esta norma (las máquinas expendedoras de productos), al establecer que "cualquier tipo de mecanismo" que ponga a disposición del consumidor ${ }^{49}$ el producto o servicio se abre la posibilidad a que dicho mecanismo sea digital ${ }^{50}$.

El elemento más característico de este tipo contractual es que el mecanismo (ya sea una máquina de vending, un programa informático...) permita al cliente adquirir tanto la propiedad como la pose-

48 Así, aunque se llame "venta automática" también es aplicable este régimen a máquinas que ejecutan otro tipo de contratos como el de arrendamiento de servicios (una máquina recreativa) o el de arrendamiento de obra (un fotomatón).

49 Entendido más bien como cliente que como consumidor en el sentido del TRLGDCU.

50 Esta es una de las dudas que se planteaba y dejaba sin resolver GÓMEZ PÉREZ, F., "Capítulo III. Venta automática. Comentario al art. 49 LOCM", en PIÑAR MAÑAS, J.L. y BELTRÁN SÁNCHEZ, E. (Dirs.) Comentarios a la Ley de ordenación del comercio minorista y a la Ley Orgánica complementaria, Civitas, Madrid, 1997, pág. 373. 
sión del producto o disfrutar del servicio de forma inmediata una vez realizado el pago sin necesidad de que intervenga persona alguna ${ }^{51}$.

En principio no todos los "contratos inteligentes" permitirían la adquisición de un producto o el disfrute de un servicio de forma automática (por ejemplo, en aquellos cuyo producto sea un contenido digital sí se podría, en el ejemplo que se ha utilizado del Via- ${ }^{52}$ también, pero si pensamos en una compraventa de un cuadro no), por lo que habría que estar al caso concreto.

Sin embargo, ¿qué se debe entender por puesta a disposición? Uno de los ejemplos típicos de "máquina de venta automática" es la de compra de billetes de autobús o la máquina de venta de entradas de cine $^{53}$. En estos ejemplos no existe ese elemento de inmediatez en cuanto a la prestación del servicio, sino que se otorga al cliente un título, un documento acreditativo de la contratación del servicio. De este modo, debemos entender que la puesta a disposición que contempla el art. 49 LOCM no se refiere únicamente a la puesta a disposición de un bien físico o la realización de un producto, sino que también cabría el reconocimiento de un derecho mediante un título (el billete de autobús). Por tanto, en cuanto que los tokens ${ }^{54}$ cumplen

51 Véase MARCO ALCALÁ, L.A., op. cit.; GÓMEZ POMAR, F. y GONZÁLEZ ORTIZ, D., "El contrato de compraventa (6). Los contratos de venta especial de la ley de ordenación del comercio minorista" en YZQUIERDO TOSLADA, M. (Dir.), Contratos - Tomo I. Contratos de finalidad traslativa del dominio (I), $1^{\text {a }}$ ed., Thomson Reuters, Cizur Menor, 2014.

52 Véase supra, en nota 27.

53 DEL ESTAL SASTRE, R., "Particularidades de la venta automática como modalidad especial de la compraventa", en CARRASCO PERERA, A. (Dir.), Tratado de la compraventa. Homenaje al profesor Rodrigo Bercovitz, Thomson Reuters, Cizur Menor, 2013, pág. 790.

54 Unidades de valor emitidas por una entidad privada que abarcan desde las criptodivisas (monedas virtuales alternativas al dinero fiduciario o FIAT) hasta bienes, contenidos digitales, servicios o derechos. El token es una representación digital de un activo, asociada a éste, que no se puede alterar (dada la naturaleza de blockchain), por lo que se garantiza que el activo representado es ése y no otro. Para más profundidad sobre el concepto de token ver: CARRASCOSA COBOS, C., "Qué es un token y para qué sirve", en https://www.bbva.com/es/quees-un-tokeny-para-que-sirve/, 7.7.2017. Sobre el concepto de moneda virtual que es introducido en la reforma de la Directiva de blanqueo de capitales (con la Directiva (UE) 2018/843 del Parlamento Europeo y del Consejo de 30 de mayo de 2018 por la que se modifica la Directiva (UE) 2015/849 relativa a la prevención de la utilización del sistema financiero para el blanqueo de capitales o la financiación del terrorismo, y por la que se modifican las Directivas 2009/138/CE y 2013/36/UE) resulta ilustrativo MORA, A., "Monedas virtuales ¿Hasta dónde llega el concepto?”, en TicsLaw, 7.1.2019 (http://ticslaw.es/monedas-virtuales/). Sobre el marco regulatorio aplicable a los distintos tipos de tokens vid. MORA, A., "Las ICOs no están reguladas... ¿O sí? Análisis jurídico de la token-economía”, en TicsLaw, 13.10.2018 (http://ticslaw.es/ las-icos-no-estan-reguladas-o-si-analisis-juridico-de-la-token-economia/). 
con esa misma función podemos entender que un contrato celebrado con un smart contract podrá ser considerado como venta automática.

En lo que al requisito del pago previo que establece el art. 49.1 LOCM se refiere, no se exige que sea pago en efectivo, basta con que "la contraprestación exigida por el dispositivo automático de venta del producto o de prestación del servicio sea, en último extremo, reconducible al dinero: tarjeta de débito o crédito, ficha, tarjeta prepago, etc" (GÓMEZ DE POMAR, F. y GONZÁLEZ ORTIZ, D.) ${ }^{55}$. Por tanto, debemos entender que el uso de tokens en los smart contracts encaja perfectamente en el requisito de pago establecido en este precepto ${ }^{56}$.

La aplicación de este régimen a los smart contracts supondría una obligación de información precontractual sobre identificación del vendedor (o prestador de servicios) y sobre la máquina y su forma de uso (art. 50 LOCM); la obligación de devolver el precio en caso de "no facilitarse el artículo solicitado" (art. 51 LOCM); y, por último, una extensión de la responsabilidad al titular del local en que esté instalada la "máquina de venta automática" (art. 52 LOCM) ${ }^{57}$.

Esta extensión de la responsabilidad es la que podría generar más dudas a la hora de aplicarse en los contratos ejecutados mediante smart contracts. ¿Qué se entiende por máquinas instaladas en un local? Podría llegar a plantearse si el establecimiento en el que se encuentran los smart contracts es la propia cadena de bloques (o el servidor, en su caso); si lo es la web en que se facilita el uso de este

55 GÓMEZ POMAR, F. y GONZÁLEZ ORTIZ, D., op. cit., págs. 568-577.

56 El uso de tokens como medio de cambio se ha admitido por la Dirección General Tributaria en varias de sus consultas vinculantes (p.e., las resoluciones a las consultas V2228-13 y V1028-15) y por el Tribunal de Justicia de la Unión Europea en la STJUE de 22 de octubre de 2015, C-264/14, EU:C:2015:718, en las que consideran exentas de IVA a las criptodivisas al aceptarlas como medio de cambio y, por tanto, considera la existencia de ciertas similitudes entre éstas y las monedas de curso legal. Para un estudio más exhaustivo de la consideración de las monedas virtuales como medio de cambio y sus implicaciones fiscales vid. FISCALIDADBTC, "El regulador vs la realidad en la valoración FIFO de los medios de cambio" en https://medium.com/@fiscalidadbtc/el-regulador-vs-la-realidad-en-lavaloraci\%C3\%B3n-fifo-de-losmedios-de-cambio-597e959bc91b, 24.9.2018 ().

57 "La responsabilidad prevista en esta regla se extiende sin duda a la recuperación inmediata del importe en caso de no obtener el producto, pero alcanza también a otras resultantes directamente de situaciones de incumplimiento o cumplimiento defectuoso por parte del vendedor automático: falta de devolución del cambio cuando la propia máquina no anuncie lo contrario, incorrecta devolución de cambio, entrega de producto distinto al solicitado, entrega de producto manifiestamente en mal estado o defectuoso. (...) La responsabilidad no alcanza, sin embargo, a la indemnización de los daños y perjuicios causados por el carácter defectuoso del producto" GÓMEZ DE POMAR, F. y GONZÁLEZ ORTIZ, D., op. cit. 
mecanismo para contratar (front-end); si lo es el servidor de hosting en que se encuentra almacenada dicha $w_{e b}{ }^{58} \ldots$

Sin embargo, esta norma está claramente concebida pensando en los contratos de venta automática en que existe un mecanismo físico (máquina de vending) y no un mecanismo completamente digital (código informático) como es el caso del smart contract. De este modo, se podrá entender que este precepto concreto no se aplicará (con carácter general) a la contratación mediante smart contracts al no estar la máquina de venta instalada en un local.

Atendiendo a todo esto, la aplicación analógica del régimen de venta automática a la contratación utilizando smart contracts parece viable.

"Además de las normas especiales sobre venta automática, al contrato le serán de aplicación las reglas contractuales que procedan, según su caracterización por motivos ajenos al elemento automático de la relación" (GÓMEZ POMAR y GONZÁLEZ ORTIZ) ${ }^{59}$. Esto supone que podrán serle de aplicación las normas del Código Civil y del Código de Comercio, además de las normas de defensa de consumidores y usuarios (en su caso). A pesar de esto, las normas sobre contratación a distancia no resultan de aplicación (ex art. 93.1) TRLGDCU).

Ahora bien, sabiendo que existe la posibilidad de que se consideren los smart contracts como venta automática habrá que plantearse si es la mejor opción, ya que, por ejemplo, al resultar este régimen excluyente del de contratación a distancia del TRLGDCU se podrán ver afectadas las garantías que tienen los consumidores en el tráfico económico cuando el proceso de contratación mediante smart contracts se realice a través de una web.

¿Qué normas aplicaremos en los casos en que confluyan los elementos necesarios para poder considerar a la contratación con smart contracts tanto venta automática como contratación a distancia?

\section{PROBLEMÁTICA}

A pesar de que, como se ha dicho, los smart contracts no se pueden considerar contratos, forman parte de la relación contractual

58 Resulta muy completo el análisis que se hace de la responsabilidad de empresas de hosting (prestadores de servicios de intermediación) en YANGUAS GÓMEZ, R., Contratos de conexión a internet, "hosting" y búsqueda: servicios de intermediación en red con consumidores, Aranzadi, Cizur Menor, 2012.

59 GÓMEZ POMAR, F. y GONZÁLEZ ORTIZ, D., op. cit. 
actuando como herramienta de ejecución. Como "nuevo" elemento técnico integrado en la relación jurídica pueden plantear una serie de retos o problemas que será necesario identificar y solucionar antes de proceder al desarrollo de un "contrato" inteligente para que se adecúe al régimen legal aplicable. De hecho, los mayores problemas no los plantea el "contrato" inteligente en sí mismo, sino su utilización en una cadena de bloques.

\section{IV.A. Cuestiones sobre ley y jurisdicción aplicable.}

Como ya se ha mencionado, el movimiento de los smart contracts está muy ligado a la tecnología blockchain y, por tanto, tiene un carácter global.

Por esta razón es imprescindible tener en cuenta las reglas del Derecho internacional privado a la hora de desarrollar un smart contract ya que, dependiendo del régimen jurídico que sea aplicable cabe la posibilidad de que la naturaleza del "contrato" inteligente cambie radicalmente ${ }^{60}$.

60 Atendiendo a las notas esenciales del derecho contractual del Common Law realmente podemos decir que el código informático, el software del "contrato" inteligente, sí que puede ser considerado como un contrato en sí mismo. De hecho, los estados americanos que están comenzando a legislar sobre esta materia (p.e., Delaware, Arizona y California) incluyen al smart contract dentro del propio concepto de contrato. En este sentido, el 31 de marzo de 2017, el Senado de Arizona aprobó la bill HB 2417 reconociendo blockchain signature y los smart contracts. Conforme a la citada aprobación se modifica la Arizona Electronic Transactions Act (AETA), incluyendo el artículo 5 en el que se define los smart contracts como: " Smart contract» means an event-driven program, with state, that runs on a distributed, decentralized, shared and replicated ledger and that can take custody over and instruct transfer of assets on that ledger". Del mismo modo está sucediendo en la legislación californiana a través de la bill no 2658 electronic records: the Uniform Electronic Transactions Act: blockchain technology. En este contexto internacional resulta interesante plantearse si los smart contracts realmente encajan en el sistema del Common Law. El fundamento de los smart contracts es crear un sistema mediante el que se garantice el cumplimiento. Mientras que en el derecho contractual inglés el principio pacta sunt servanda es más difuso. Para el derecho contractual inglés no existe una obligación de cumplimiento contractual, sino que las partes únicamente se obligan a indemnizar por los daños ocasionados por el incumplimiento ("The duty to keep a contract at common law means a prediction that you must pay damages if you do not keep it - and nothing else", HOLMES, O. W., "The path of the law" en 10 Harvard Law Review 457, 1897). De hecho, por esta razón están prohibidas las cláusulas penales en sus contratos, ya que penalizan el incumplimiento incentivando así que se cumpla el contrato, aunque exista una oferta mejor "sobre la mesa" (véase la sentencia Cavendish v. Makdessi y ParkingEye v. Beavis UKSC de 4 de noviembre de 2015 (https://www.supremecourt.uk/cases/docs/uksc-2013-0280-judgment.pdf.

(C) UNED. Revista de Derecho UNED, núm. 27, 2021 
De este modo, será muy importante a la hora de desarrollar el smart contract tener en cuenta la jurisdicción y la ley que serán aplicables en la fase precontractual, al propio contrato y a cualquier conflicto que surja a partir de la relación jurídica de modo que las partes se vean beneficiadas por su elección.

Así, el principio de autonomía conflictual se ve reconocido casi en la totalidad de los sistemas de Derecho Internacional Privado ${ }^{61}$, por lo que si las partes indican cuál será la ley y jurisdicción aplicable no habrá problema alguno, se atenderá a lo acordado por ellas (así se contempla en diversos textos internacionales como en el art. 3.1 Roma I ${ }^{62}$ o en el art. 7 de la Convención de México ${ }^{63}$ ).

En el caso en que las partes no lo hayan acordado comienza a haber más complicaciones, pero si son identificables podremos acudir a normas generales del derecho internacional privado ${ }^{64} \mathrm{y}$ establecer la ley y jurisdicción aplicable en función de la residencia habitual del vendedor o el prestador del servicio, en el lugar donde se encuentre el inmueble... (p.e., art. 4 Roma I).

El mayor problema surge cuando las partes del contrato no sean identificables ${ }^{65}$. En este caso se podría atender al lugar en que se ejecuta el contrato. Sin embargo, si el smart contract se ejecuta sobre una red blockchain éste estará en todos los ordenadores que formen parte de la red. En este caso resultará difícil elegir el fuero y la ley aplicable.

61 VAQUERO LÓPEZ, C., "Autonomía de la voluntad y normas imperativas”, en SÁNCHEZ LORENZO, S. (edit.), Derecho contractual comparado. Una perspectiva europea y transnacional. Tomo II, 3. ${ }^{\text {a }}$ ed., Thomson Reuters, Cizur Menor, 2016, pág. 95-104.

62 Reglamento (CE) n. ${ }^{\circ}$ 593/2008 del Parlamento Europeo y del Consejo, de 17 de junio de 2008, sobre la ley aplicable a las obligaciones contractuales (Roma I).

63 Convención interamericana sobre derecho aplicable a los contratos internacionales (México, 17 de marzo de 1994).

${ }_{64}$ GARCIMARTÍN ALFÉREZ, F. J., Derecho Internacional Privado, Civitas, $3^{\text {a }}$ ed. 2016, y CALVO CARAVACA, A. L. y CARRASCOSA GONZÁLEZ, J., Derecho internacional privado, $15^{\mathrm{a}}$ ed., Comares, 2016, págs. 133-348.

65 Por ejemplo, la moneda virtual Monero está basada en un sistema que, en principio, no permite la trazabilidad de las transacciones realizadas, con lo que se busca aumentar la privacidad de quien la utiliza con el fin de conseguir su anonimato (https://www.getmonero.org/). 


\section{IV.B. Cuestiones relativas a la formación del contrato.}

\section{IV.B.1). Identificación y capacidad de las partes.}

Cuando se habla de smart contracts uno de los primeros problemas que salen a relucir siempre es la problemática de identificación de las partes y, por tanto, la imposibilidad de verificar su capacidad.

Ciertamente el no poder verificar la capacidad de las partes contratantes puede tener graves consecuencias como la anulabilidad del contrato (lo que supone un problema técnico para los contratos sobre la cadena de bloques).

Sin embargo, no son cuestiones nuevas. Pasó ya con las máquinas expendedoras de tabaco en su día. Ahora cuando se verifica la edad del comprador se pulsa un botón para activar la máquina ${ }^{66}$. En el ciberespacio pasaba lo mismo. Cuando se creó internet no existía ningún procedimiento de verificación de la identidad de las personas, el ciberespacio nació anónimo y libre y ahora hay quienes dicen que, por ejemplo, "Con 150 likes el algoritmo de aprendizaje automatizado (de Facebook) puede detectar tu personalidad y con 200 te conoce más que tu pareja. Y con 250 likes puede saber más de ti que tú mismo" 67.

La solución a estos problemas pasó por desarrollar sistemas que permitieran verificar la capacidad de las personas. Se crearon credenciales como la firma electrónica ${ }^{68}$.

Con blockchain y los smart contracts encontramos un paralelismo enorme con los orígenes del ciberespacio ${ }^{69}$. La cadena de blo-

66 En Italia, por ejemplo, para poder comprar tabaco en una máquina automática hay que insertar en la máquina el códice fiscale (una tarjeta de residencia) para verificar la mayoría de edad.

67 HILBERT, M., en la entrevista que le hicieron en LANDULCE, E., "Entrevista a Martin Hilbert. El gurú del "Big Data": Facebook sabe más de ti con 250 likes que tú mismo”, El Mundo, 27.11.2017 (vid. en: http://www.elmundo.es/papel/futuro/201 7/11/27/5a1ab61322601dd03b8b4603.html).

68 La legislación en esta materia siempre ha tratado de dotar a la firma electrónica los mismos efectos que a la firma manuscrita. Sin embargo, el Reglamento (UE) $N^{\circ}$ 910/2014 del Parlamento Europeo y del Consejo de 23 de julio de 2014 relativo a la identificación electrónica y los servicios de confianza para las transacciones electrónicas en el mercado interior y por la que se deroga la Directiva 1999/93/ CE (Reglamento eIDAS) establece varios niveles de fiabilidad de los sistemas de firma electrónica con distinta credibilidad a efectos probatorios (firma electrónica, firma electrónica avanzada y firma electrónica cualificada) en función del nivel de seguridad y de certificación de los sistemas de identificación electrónica (bajo, sustancial y alto).

69 A lo largo de la obra El Código 2.0 (LESSIG, L. Código 2.0, Traficantes de sueños, Madrid, 2006) se nos explica de una forma clara cómo ha cambiado Inter- 
ques nace inspirada por el movimiento cypherpunk mediante el que se defiende el uso de la criptografía para mejorar la privacidad como medio de cambio social y político. De hecho, una de las características originales de las distributed ledger technologies (DLT) era el anonimato ${ }^{70}$. Sin embargo, ya existen iniciativas que buscan servir como credenciales en blockchain para identificar a las partes que realicen transacciones o contraten a través de esta red $^{71}$; además de que existen métodos para trazar las transacciones realizadas e identificar al usuario ${ }^{72}$.

Este problema, por tanto, pasa realmente por incorporar elementos técnicos que faciliten la identificación de los contratantes como sucedió tanto con las máquinas expendedoras como en Internet, lo que no está fuera del alcance de la tecnología actual ${ }^{73}$.

\section{IV.B.2). Vicios en el consentimiento.}

Muy ligado al problema anterior se encuentra la dificultad para verificar si el consentimiento emitido ha sido válido o no en los ca-

net desde sus orígenes hasta 2009 a través de la influencia del poder del mercado y de los estados. Cómo por la exigencia de regular las relaciones y el comportamiento en el ciberespacio se fue modificando una red que nació como un simple protocolo para enviar y recibir datos (sin que se diera información sobre quién había hecho qué ni dónde) hasta el punto actual en que es posible trazar hasta los gustos de las personas que envían dichos datos.

70 Existen cadenas de bloques en las que esta anonimidad es más real que en otras. Por ejemplo, la red que sustenta la criptodivisa Monero está más inspirada en esta idea de realizar transacciones anónimas. Mientras tanto, existen otras cadenas en las que para utilizarlas es necesario identificarse (p.e., las permisionadas) o en las que, a pesar de ser abiertas existe una pseudo-anonimidad, ya que, aunque en principio no se pueda identificar a la persona que opere a través de esa red sí se puede trazar su actividad para acabar identificándola. Esto es lo mismo que pasa en internet. Existen mecanismos para proteger más la privacidad y poder navegar de forma anónima, sin que puedan rastrear la localización... (p.e., utilizando VPNs, el navegador TOR...).

${ }^{71}$ Como el proyecto de identidad digital de Alastria (https://alastria.io/assets/resources/AlastriaIdentidad.pdf).

72 Lo mismo ha pasado con las direcciones IP que en un principio no permitían identificar al usuario y, con el tiempo, incluso se han llegado a considerar datos de carácter personal en determinadas situaciones (vid. DE MIGUEL ASENSIO, P.A., op. cit., pág. 312).

73 En esta línea va a jugar un papel fundamental la aplicación de la nueva Directiva de prevención de blanqueo de capitales, ya que, por ejemplo, obligará a la identificación de quienes operen con "casas de cambio de monedas virtuales" o exchanges. Esto supone que en caso de que se deriven problemas en la relación jurídica se podrá trazar las "cuentas" vinculadas al smart contract hasta el momento de la operación con un Exchange y solicitar (mediante vía judicial) la identificación de su titular. 
sos en que el proceso contractual no sea presencial o se realice de forma anónima.

A pesar de que existan o se puedan crear mecanismos de identificación de las partes, estos realmente no garantizan que el consentimiento emitido sea válido. Únicamente acreditan que quien ha emitido el consentimiento es quien dice ser e incluso que tiene capacidad de obrar. Sin embargo, la firma electrónica no puede verificar que el consentimiento ha sido plenamente consciente o plenamente libre (otra vez más, uno de los problemas inherentes a la contratación integrando smart contracts no presenta novedad alguna más allá de lo que ya sucede con la contratación electrónica habitual ${ }^{74}$ ).

El mayor problema que genera la existencia de vicios en el consentimiento en los smart contracts no es su detección, sino sus consecuencias contractuales: la nulidad o la anulabilidad.

Dada la naturaleza inmutable que tiene la cadena de bloques, una vez introducido y activado el código del smart contract ya no se podrá modificar y el contrato se ejecutará automáticamente en cuanto se cumplan las condiciones previstas. Al no poder modificar ni eliminar el "contrato" de la cadena de bloques (ya que si cambiamos dicho smart contract sería necesario modificar absolutamente todos los bloques de transacciones posteriores) no se podrá paralizar la ejecución del mismo a pesar de que sea anulable. Como consecuencia, a pesar de que el contrato fuera declarado nulo o anulable por un Juez habría que esperar a que se ejecute y, ex post, se deberían producir los efectos de forma restitutiva ${ }^{75}$, aunque puede ser complicado trasladar los efectos a la cadena de bloques.

Ahora bien, en cuanto que el smart contract es un programa informático cabe la posibilidad de insertar variables que sirvan como vía de escape para todas las situaciones que puedan derivar en la resolución de un contrato, paralizando la ejecución hasta que haya una resolución judicial o incluso resolviendo directamente la relación contractual (por ejemplo, mediante un sistema multifirma que actúe como una especie de "botón del pánico" o, en otros supuestos, se podría llegar a automatizar la resolución del contrato mediante

74 De hecho, este problema se está tratando de abordar por parte de la Unión Europea con la inserción de la autenticación reforzada (o SCA) a través de la Directiva (UE) 2015/2366 del Parlamento Europeo y del Consejo de 25 de noviembre de 2015 sobre servicios de pago en el mercado interior y por la que se modifican las Directivas 2002/65/CE, 2009/110/CE y 2013/36/UE y el Reglamento (UE) no 1093/2010 y se deroga la Directiva 2007/64/CE (PSD2).

75 En este sentido WERBACH, C., CORNEL, K., op. cit., pág. 376. 
la incorporación de oráculos -véase casos de fuerza mayor expresamente contemplados por las partes-).

IV.B.3). Discrepancias entre el acuerdo y el código.

Si documentando las relaciones contractuales en lenguaje natural ya es común encontrar discrepancias entre lo plasmado y lo acordado realmente por las partes teniendo que acudir frecuentemente a mecanismos de interpretación e integración del contrato, obviamente este problema se intensificará cuando un acuerdo se represente en lenguaje máquina.

En caso de existir discrepancias entre el acuerdo y el código no cabe duda, como ya se ha dicho, de que siempre primará el acuerdo de voluntades (el contrato) al ser el código (smart contract) una mera plasmación de éste y que, por tanto, puede ser defectuosa. A su vez, si existe una plasmación del acuerdo en lenguaje natural (por ejemplo, mediante condiciones generales en una página web que sirva como frontend para que interactúe el usuario con el smart contract) ésta debería primar sobre el código al presentarse en lenguaje natural y, por tanto, ser más comprensible para el usuario, pero a su vez estará subordinada al acuerdo de las partes y, obviamente, a las normas imperativas.

Ahora bien, a pesar de que en el plano teórico esté clara la jerarquía entre contrato y su documentación, en la práctica el problema vuelve a derivar de la naturaleza inmutable de la cadena de bloques y la autoejecución del smart contract una vez que se ha activado.

De este modo, si no se establece un sistema que permita al menos paralizar la ejecución, una discrepancia entre lo acordado y lo plasmado en el código podría derivar en situaciones que no supongan alteración alguna de las prestaciones esenciales del contrato, hasta situaciones más complejas como que se haya establecido un precio distinto al pactado y se ejecute el contrato.

Está claro que si estas discrepancias generan algún daño deberá responder por éste quien haya producido el perjuicio ${ }^{76}$ (art. 1101 CC -responsabilidad contractual- e incluso el 1902 CC -responsabilidad extracontractual-). Aun así, es fácil encontrar situaciones en que sea

76 En cuanto a la responsabilidad por daños ocasionados por defectos en el desarrollo de software es remito, entre otros, a SOLER MATUTES, P. (Dir.), Manual de gestión y contratación informática, Thomson Reuters, Cizur Menor, 2006, págs. 669-722. 
complicado identificar al responsable del daño ya que intervienen varios actores en la relación jurídica: los contratantes; el programador que crea el smart contract; un jurista; etc.

Este problema no se limita únicamente a los actores principales de la relación jurídica (las partes contratantes y los encargados de elaborar el software), sino que cabe que se generen problemas de este tipo con la introducción de oráculos (fuentes de información para que el smart contract verifique el cumplimiento de las condiciones establecidas para la ejecución).

Y en cuanto se vaya incrementando el uso de las plataformas que permiten la generación de smart contracts sin necesidad de progra$\operatorname{mar}^{77}$ (que podrían denominarse como plataformas de "smart contracts as a service -SCaaS-"78) habrá más problemas a la hora de identificar al responsable, pues a la hora de desarrollar el smart contract ya no actúa sólo el informático, sino que los propios contratantes realizarán una labor activa en ese proceso.

Será necesario tener muy en cuenta a la hora de integrar este tipo de mecanismos en la contratación las posibles dificultades para encontrar al responsable del daño ocasionado. Así las cosas, deberían tomarse medidas de prevención como la realización de auditorías del código o pruebas de concepto para comprobar que los parámetros establecidos son correctos y el proceso de ejecución será el idóneo.

Si bien la regla general es tratar de individualizar la responsabilidad en los sujetos que hayan ocasionado efectivamente el daño (atendiendo a la relación de causalidad) hay casos en los que no es tan sencillo determinar un responsable concreto (bien sea porque han intervenido varios sujetos en la causación del daño -concurrencia de causas-, porque el causante del daño ha sido un miembro indeterminado de un grupo, porque el daño ha sido resultado de una actuación de uno o varios sujetos dentro de una empresa...).

Este problema de imputación de la causa del daño puede ser uno de los problemas más importantes que surjan en la contrata-

77 Actualmente existen varios tipos de estas plataformas, por ejemplo, "Agrello" (vid. https://www.agrello.io/) y "SmartContract" (vid. https://www.smartcontract.com/).

${ }^{78}$ Haciendo una adaptación de la terminología utilizada en para los distintos tipos prestación de servicios de cloud computing (Infrastructure as a Sercive -IaaS-; Platform as a Service -PaaS-; y Software as a Service -SaaS-). Vid. https://www.interoute.es/what-iaas. 
ción utilizando smart contracts como herramientas de ejecución del contrato ${ }^{79}$.

De este modo, en caso de no poder individualizar la responsabilidad entre los intervinientes en el proceso de desarrollo del smart contract, la solución pasa porque todos ellos asuman la responsabilidad solidaria ${ }^{80}$. En este sentido, es totalmente clara y aplicable al supuesto planteado la STS de 12 de diciembre de 1985 cuando dice que "en los casos de ser imposible o de difícil discriminación separar las respectivas responsabilidades de los intervinientes en el proceso constructivo de una obra (constructor, contratista, arquitecto, aparejadores), se ha de imponer y exigir su responsabilidad solidaria, con la finalidad pragmática de no dejar inermes los intereses en pugna".

\section{BUENAS PRÁCTICAS PARA LA INTEGRACIÓN DE SMART CONTRACTS EN LAS RELACIONES JURÍDICAS}

Como se ha visto en el punto anterior, la mayor parte de los problemas que presenta la contratación integrando smart contracts no es tan novedosa, sino que son en gran medida los mismos que ya se plantearon en su momento con la utilización de Internet como medio para contratar.

79 De hecho, el problema de la incertidumbre causal del daño es uno de los mayores problemas que encontramos en el Derecho de responsabilidad civil o Derecho de daños (en este sentido, REGLERO CAMPOS, L. F. "Lección 4. ${ }^{\text {a }}$ El nexo causal. Las causas de exoneración de responsabilidad: culpa de la víctima y fuerza mayor. La concurrencia de culpas", en BUSTO LAGO, J.M., REGLERO CAMPOS, L.F., (Coords.), Lecciones de responsabilidad civil, 2. ${ }^{\mathrm{a}}$ ed., Thomson Reuters, Cizur Menor, 2013, pags. 115-118).

${ }_{80}$ Así se destaca, también, en la STS 388/2008 de 20 de mayo recopilando extensa jurisprudencia relativa a la aplicación de responsabilidad solidaria cuando existe imposibilidad de individualizar responsabilidades cuando dice: "Es reiterada la jurisprudencia que declara que existe solidaridad impropia entre los sujetos a quienes alcanza la responsabilidad por el ilícito culposo, con pluralidad de agentes y concurrencia de causa única. (...) obedece a razones de seguridad e interés social, en cuanto constituye un medio de protección de los perjudicados adecuado para garantizar la efectividad de la exigencia de la responsabilidad extracontractual, pero exige para su aplicación que no sea posible individualizar los respectivos comportamientos ni establecer las distintas responsabilidades (...) y se encuadra en el contexto de la regulación seguida por muchos códigos europeos(...)”. Sobre este concepto se habla también, p.e., en la STS de 13 de julio de 2017 (sobre quién debe ser responsable en un caso de absorción de entidades bancarias -el Banco Sabadell o una Fundación-) y en la STC de 14 de abril de 2016 (en que se estudia la compatibilidad de la responsabilidad de miembro indeterminado de un grupo con el derecho a la huelga). 
Sin embargo, es cierto que las características de blockchain y los "contratos inteligentes" suponen algún reto novedoso precisamente por la unión entre la naturaleza inmutable de la cadena de bloques y el automatismo de los smart contracts. Aún con esto, la solución si no a todos, a la mayoría de los problemas que puede ocasionar este pseudotipo de contratación (contratación legal inteligente) pasa, en mayor o menor medida, por la previsibilidad de los mismos y la integración de elementos técnicos que eliminen el riesgo de que se generen problemas, o bien que establezcan una vía de escape a la ejecución automática.

De este modo, después de haber estudiado el fenómeno de los smart contracts se podría elaborar una guía de buenas prácticas con la finalidad de evitar ulteriores problemas jurídicos que deriven en la actuación de los tribunales (pues el smart contract surge, en gran medida, para evitar acudir a estos a la hora de llevar a cabo la ejecución contractual ${ }^{81}$ ) y, en caso de que no se pueda evitar, generar mecanismos que faciliten su labor.

1. Será conveniente que además de plasmarse el acuerdo en el código informático, el contrato también se documente de una forma comprensible para la generalidad de los usuarios en lenguaje humano (ya sea mediante unas condiciones generales, mediante la exposición en una página web del funcionamiento del smart contract y todas sus posibles consecuencias, un vídeo, etc.). Cuanto más claro quede el funcionamiento del smart contract antes de que las partes se vinculen contractualmente, mejor (para cumplir los debidos estándares de transparencia e información precontractual).

2. Siguiendo en la línea de lo expuesto en el anterior párrafo, podría ser conveniente que a la hora de llegar al acuerdo y plasmarlo en lenguaje humano se especifique la funcionalidad del smart contract como elemento esencial del contrato. A su vez, que se obligue a la aceptación expresa de las cláusulas que establezcan que la ejecución del contrato se desarrollará a través de este mecanismo y las cláusulas en que se explique su funcio-

81 Hay quienes sostienen que el smart contract no tiene sentido si lo que se trata es de cumplir con los requisitos legales y que estos y la cadena de bloques nacen para actuar al margen de la legalidad (vid. FISCALIDADBTC, "Los contratos inteligenes... op. cit.). Sin embargo, en la medida en que tienen efectos sobre el mundo físico y no se limitan al ciberespacio (ya que su finalidad última es la de facilitar el cumplimiento de relaciones obligatorias) no cabe negar que deberán tenerse en consideración las disposiciones legales para que tengan validez. 
namiento ya que, de no ser así, será difícil que los contratantes comprendan las implicaciones que conlleva la inserción del smart contract (al estar éste redactado en lenguaje informático) y, por consiguiente, podrían darse situaciones en las que se anule el contrato por existir vicios en el consentimiento. Esto será mucho más necesario en caso de contratación con consumidores para proteger la subsistencia del contrato, por lo que será necesario plasmar las acciones que realizará el código informático de forma inteligible para las partes.

Así, teniendo en cuenta lo complicado que puede llegar a ser el sistema de automatización del cumplimiento de un contrato, es necesario establecer todos los mecanismos de transparencia que sean posibles para mejorar la experiencia contractual y evitar que nazcan problemas de interpretación o de error en el consentimiento. Aunque integrarlo como elemento esencial del contrato pueda suponer en los casos de contratación con consumidores la pérdida de la posibilidad de hacer un control de contenido de tales cláusulas, seguirá siendo posible el control de transparencia ${ }^{82}$ y se facilitará al usuario conocer mejor las implicaciones que supone el integrar un smart contract en el contrato. Asimismo, en caso de discrepancias entre lo acordado y lo trasladado al código será más fácil que se resuelva el contrato por incumplimiento de un elemento esencial, lo que genera una mayor seguridad para las partes a la hora de lidiar ante problemas de adaptación del acuerdo al lenguaje máquina.

3. En aras de conseguir esta transparencia, sería interesante permitir el acceso al código fuente del smart contract de forma libre para que se pueda realizar una auditoría del mismo y así analizar sus vulnerabilidades, si de verdad coincide con lo que se ha pactado, etc.

82 Vid. STJUE 21 de diciembre de 2016, C-154/15, C-307/15 y C-308/15, EU:C:2016:980 y las sentencias del Tribunal Supremo posteriores a ésta (p.e., SSTS de 24 de febrero de 2017 y de 25 de mayo de 2017) en las que se va construyendo el control de transparencia. Asímismo, se realiza un análisis muy interesante sobre este criterio de control de condiciones generales en CÁMARA LAPUENTE, S., "Las (seis) SSTS posteriores a la STJUE 21 diciembre 2016. El control de transparencia sigue en construcción, muta y mutará aún más: hacia la transparencia subjetiva (Comentario a las SSTS de 24 febrero 2017, 9 marzo 2017, 20 abril 2017 y 25 mayo 2017)", en Boletín del Colegio de Registradores de España, 42, junio 2017, págs. 1770-1790 (https://www. unirioja.es/dptos/dd/civil/docs/2017_Camara_Comentario_SSTS_2017_transparencia_post_STJUE_21_12_2016.pdf). En este sentido, también CARRASCO PERERA, A., "De nuevo sobre el control de transparencia y el control de contenido en contratos celebrados entre no consumidores", en Revista CESCO de Derecho de Consumo, N. ${ }^{\circ}$ 21/2017 (https://www.revista.uclm.es/index.php/cesco/article/view/1419). 
4. En la medida en que la naturaleza de estos contratos es eminentemente internacional, será importante establecer una cláusula de jurisdicción aplicable.

5. Como ya se ha dicho en el apartado anterior, puede ser conveniente integrar rutas de escape para paralizar o resolver el contrato en caso de que surja cualquier tipo de problema en cuanto al cumplimiento de las prestaciones o la validez del contrato en sí mismo.

6. También será conveniente que las partes se identifiquen a la hora de llevar a cabo el proceso de contratación utilizando sistemas de firma electrónica para facilitar la solución de los problemas que puedan surgir de la relación contractual.

Obviamente esto no es una lista cerrada de soluciones ${ }^{83}$ ya que cada contrato será único y habrá que tener en consideración todas las circunstancias concretas que puedan afectar a cada caso. Asimismo, a modo de ejemplo hay quienes han propuesto otras soluciones como establecer un seguro para los casos en que haya cualquier fallo en la ejecución contractual que provoque algún de daño a alguna de las partes; o que la cadena de bloques que se utilice sea privada ${ }^{84}$.

El único modo de que un smart contract funcione realmente es que se realice contemplando todas las posibles circunstancias que puedan incidir en su ejecución y conceptualizándolo de la forma más simple y completa posible, eliminando cualquier tipo de cláusula que lleve a la interpretación.

Es cierto que esto es algo a lo que no estamos acostumbrados en las culturas jurídicas de Derecho continental ${ }^{85}$. Sin embargo, en ma-

83 Por ejemplo, cuando se realicen transacciones con tokens (sobre todo con criptodivisas) es importante tener en cuenta su fluctuación. Por tanto, será conveniente que el precio se exprese en moneda fiduciaria y se indique el o los tokens concretos que se admitirán como medio de cambio. Asimismo, será conveniente que quede claro el riesgo de fluctuación del precio que están dispuestas a asumir las partes para realizar la transacción y se establezca un sistema de control del mismo dentro del smart contract (un oráculo que determine el precio del token elegido en el momento de cumplimiento).

${ }_{84}$ GORDO VILLANUEVA, M., "Smart contracts y la tecnología blockchain en el derecho contractual”, en Revista Digital Nuevas Tecnologías, n. ${ }^{\circ}$ 12, diciembre, 2017.

85 Esto lo expresa muy bien SANCHEZ LORENZO, S., "Contrato interno e internacional: claves de la diferencia” en HORNERO MÉNDEZ, C. (Dir.), op. cit., pág. 91 al decir que "cuando hablamos del régimen jurídico de los contratos internacionales, un jurista continental pensará inmediatamente en términos de conflicto o controversias. Si el contrato internacional no se cumple, habrá que plantearse su régimen jurídico, es decir, dónde litigar y bajo qué normativa. Si hablamos del mismo 
teria de smart contracts es preferible que esta actitud cambie y se trate de trabajar de una forma preventiva dada su naturaleza irreversible e inmodificable. Si no se tienen en cuenta los posibles problemas que pueden surgir en la fase precontractual y no se aplican soluciones dentro del código, una vez que se comience a ejecutar el contrato (en principio ${ }^{86}$ ) no hay vuelta atrás.

\section{CONCLUSIONES.}

A través de estas escasas páginas se ha tratado de abordar una de las tecnologías que están en boca tanto de juristas como de tecnólogos y empresarios. Concebida por unos como una revolución en el ámbito contractual que hará desaparecer a juristas y por otros como algo totalmente ajeno al ámbito jurídico.

Tras este breve análisis y, a modo de resumen, se espera que se hayan podido desprender, al menos, las siguientes conclusiones:

1. El smart contract en sentido estricto es código, un programa informático que permite la ejecución de determinadas prestaciones de un contrato. Por tanto, su naturaleza no es contractual, sino que el "contrato inteligente" es simplemente un medio de plasmación de un contrato (naturaleza documental) que realiza a su vez las funciones de instrumento de ejecución de las obligaciones de un contrato (naturaleza ejecutiva).

Que debido a que su naturaleza es más bien tecnológica, su integración en una relación contractual no va a afectar al régimen jurídico aplicable a la relación contractual de que se trate.

2. Como consecuencia de la confusión generada alrededor del concepto de smart contract al entenderse generalmente como cualquier código informático que se despliegue sobre una red blockchain, puede ser interesante utilizar el concepto de "contrato legal inteligente" para hablar de los smart contracts cuya última función es servir como herramienta de ejecución contractual.

\footnotetext{
asunto a un jurista anglosajón, probablemente retrotraiga sus temores a un momento muy anterior al litigio: se preguntará cómo es preciso redactar un contrato internacional para evitar el litigio y asegurar la protección de las partes".

86 Digo en principio porque existe la posibilidad de que la cadena de bloques se modifique si existe un consenso suficiente como sucedió en el caso de TheDAO (para saber más del caso véase https://www.xataka.com/seguridad/the-dao-y-el-caso-delrobo-de-los-50-millones-de-dolares-enethereum-insert-coin-1x01). De hecho, esta es una de las razones por las que se comenzaron a crear cadenas de bloques privadas o permisionadas (para saber más vid. http://libroblockchain.com/blockchain-privada/).
} 
3. A su vez, se está tratando de construir a través de este término una pseudocategoría contractual diferenciada por la integración en un contrato de un elemento técnico como es el smart contract (del mismo modo que se hizo al crear la categoría de venta automática o de contratación electrónica). Esto no es necesario; sin embargo, podría resultar útil establecer unas reglas básicas para generar mayor seguridad jurídica cuando se contrate integrando estas herramientas de ejecución obligacional.

4. Puede tener cabida la aplicación del régimen jurídico de la venta automática a los smart contracts. Sin embargo, en caso de integrarlos en esta categoría jurídica se excluye la aplicación de las normas de consumo relativas a la contratación a distancia o fuera de establecimiento mercantil y, por tanto, en caso de relaciones con consumidores su protección se podría ver mermada.

5. De la aplicación de esta tecnología a las relaciones contractuales surgen diversos problemas jurídicos. Sin embargo, gran parte de ellos no resultan del todo novedosos, repitiéndose patrones de problemas que ya se han resuelto para otras tecnologías (como Internet).

Además, estos problemas se pueden evitar o resolver en mayor o menor medida incorporando elementos técnicos y manteniendo una actitud preventiva a la hora de su desarrollo. Cuanto más completo (que se contemple la mayor cantidad posible de circunstancias que podrán incidir en alguna medida en la contratación) y simple (evitando así la interpretación) sea el smart contract, menos probable será que surjan problemas a la hora de su ejecución (algo que ya pasa, por otro lado, en la contratación internacional).

Este trabajo de investigación se ha realizado "para evitar el peligro de que los espíritus demasiado apegados a la magia de los nombres vayan a imaginar que lo que aquí se diga deja de valer cuando alteramos las rúbricas de las cosas, en el error de estimar como perro nuevo lo que es collar reciente. $Y$ esta historia va de perros, no de collares" (CARRASCO PERERA) ${ }^{87}$. Estas palabras resumen, en gran medida, un patrón que suele cumplirse a la hora de estudiar los retos de la innovación, tanto desde la perspectiva jurídica como desde la tecnológica.

87 CARRASCO PERERA, A., "Reivindicación y defensa de la vieja doctrina rebus sic stantibus. Sentencia de 15 de octubre de 2014", en Revista Cuadernos Civitas de Jurisprudencia Civil, n. ${ }^{\circ}$ 98, 2015, pág. 184.

(C) UNED. Revista de Derecho UNED, núm. 27, 2021 
Tabla de jurisprudencia.

\begin{tabular}{|c|c|c|}
\hline Temática general & Temática & Sentencia \\
\hline $\begin{array}{l}\text { Régimen juridico de } \\
\text { los tokens }\end{array}$ & $\begin{array}{l}\text { Calificación de las monedas } \\
\text { virtuales a efectos de IVA }\end{array}$ & $\begin{array}{l}\text { STJUE de } 22 \text { de octubre de } \\
\text { 2015, C-264/14, EU:C:2015:718, }\end{array}$ \\
\hline \multirow{4}{*}{ Responsabilidad } & \multirow{4}{*}{ Responsabilidad solidaria } & STS de 12 de diciembre de 1985 \\
\hline & & STS 388/2008 de 20 de mayo \\
\hline & & STS de 13 de julio de 2017 \\
\hline & & STC 14 de abril de 2016 \\
\hline \multirow[t]{3}{*}{ Cláusulas abusivas } & \multirow{3}{*}{$\begin{array}{l}\text { Control de transparencia } \\
\text { vs. Control de contenido }\end{array}$} & $\begin{array}{l}\text { STJUE de } 21 \text { de diciembre } \\
\text { de } 2016 \text {, C-154/15, C-307/15 y } \\
\text { C-308/15, EU:C:2016 }\end{array}$ \\
\hline & & STS de 24 de febrero de 2017 \\
\hline & & STS de 25 de mayo de 2017 \\
\hline
\end{tabular}

\section{BIBLIOGRAFÍA.}

Argelich Comelles, C., "Smart contracts o Code is Law: soluciones legales para la robotización contractual”, en InDret, 2/2020.

Bourque, S.; Fung Ling Tsui, S., "A lawyer's introduction to smart contracts”, en Scientia Nobilitar Reviewed legal studies, 2014.

BUTERIN, V., Ethereum whitepaper. A next generation smart contract \& decentralized application platform, 2014 (http://www.the-blockchain.com/docs/Ethereum_white_paper-a_next_generation_ smart_contract_and_decentralized_application_platform-vitalikbuterin.pdf).

Calvo Caravaca, A. L. y Carrascosa González, J., Derecho internacional privado, 15 a ed., Comares, 2016.

CÁmARA LAPUENTE, S., "La nueva protección del consumidor de contenidos digitales tras la Ley 3/2014, de 27 de marzo", en Revista CESCO de Derecho de Consumo, ${ }^{\circ} 11 / 2014$.

CÁmara Lapuente, S., "Las (seis) SSTS posteriores a la STJUE 21 diciembre 2016. El control de transparencia sigue en construcción, muta y mutará aún más: hacia la transparencia subjetiva (Comentario a las SSTS de 24 febrero 2017, 9 marzo 2017, 20 abril 2017 y 25 mayo 2017)", en Boletín del Colegio de Registradores de España, 42, junio 2017, págs. 1770-1790 (https://www.unirioja.es/dptos/dd/ civil/docs/2017_Camara_Comentario_SSTS_2017_transparencia_ post_STJUE_21_12_2016.pdf). 
Carrasco Perera, A. (Dir.), Tratado de la compraventa. Homenaje al profesor Rodrigo Bercovitz, Thomson Reuters, Cizur Menor, 2013.

Carrasco Perera, A., "Reivindicación y defensa de la vieja doctrina rebus sic stantibus. Sentencia de 15 de octubre de 2014", en Revista Cuadernos Civitas de Jurisprudencia Civil, n. ${ }^{\circ}$ 98, 2015.

Carrasco Perera, A. (Dir.), Cordero lobato, E. y Marín López, M.J., Lecciones de Derecho Civil. Derecho de obligaciones y contratos en general, 2. ${ }^{\mathrm{a}}$ ed., Tecnos, Madrid, 2016.

Carrasco Perera, A., "De nuevo sobre el control de transparencia y el control de contenido en contratos celebrados entre no consumidores", en Revista CESCO de Derecho de Consumo, N. ${ }^{\circ}$ 21/2017 (https://www.revista.uclm.es/index.php/cesco/article/view/1419).

Carrasco Perera, A., Derecho de contratos, Aranzadi, 2. ${ }^{\text {a }}$ ed., Cizur Menor, 2017.

CASTiÑEIRA JeREZ, J., "Pacta Sunt Servanda, imprevisión contractual y alteración sobrevenida de las circunstancias" en Revista de Derecho Patrimonial, n. ${ }^{\circ}$ 29/2012.

CASTIÑEIRA JeREZ, J., El incumplimiento justificado del contrato ante el cambio de circunstancias, Tirant lo Blanch, Valencia, 2017.

CunIBERTI, G., "The International Market for Contracts: The Most Attractive Contract Laws", en Northwestern Journal of International Law \& Business, vol. 34, Iss. 3, 2014 (https://scholarlycommons.law. northwestern.edu/cgi/viewcontent.cgi?article=1767\&context=njilb).

Davara Fernández De Marcos, E., "Los smart contracts", en Actualidad Administrativa, núm. 7, Julio-Agosto 2017, (LA LEY 6734/2017).

De Miguel Asensio, P.A., Derecho privado de internet, $5^{\mathrm{a}}$ ed., Thomson Reuters, Madrid, 2015.

De Pablo Contreras, P., "Capítulo 5. Incumplimiento de las obligaciones y responsabilidad contractual”, en MARTÍNEZ DE AGUIRRE ALDAZ, C. (Coord.), Curso de Derecho Civil (II). Volumen I. Teoría general de la obligación y el contrato, $5^{\mathrm{a}}$ ed., Edisofer, Madrid, 2018.

Díez-Picazo Y Ponce De León, L., Fundamentos de Derecho civil patrimonial, vol. I, 6 ${ }^{\mathrm{a}}$ ed., Thomson-Civitas, Cizur Menor, 2009.

Díez-Picazo Y Ponce De León, L.; Gullón, A., Sistema de Derecho Civil. Volumen II. El contrato en general. La relación obligatoria, $11 .^{a}$ ed., Tecnos, Madrid, 2016. 
ECHEBARRÍA SAÉNZ, M., “Contratos electrónicos autoejecutables (smart contracts) y pagos con tecnología blockchain", en Revista de estudios europeos, núm. 70, julio-diciembre 2017.

EU BLOCKCHAIN OBSERVATORY AND FORUM, Legal and regulatory framework of blockchain and Smart contracts, 27.9.2019, pags. 23 y ss. (https://www.eublockchainforum.eu/reports).

Feliu ReY, J., "Smart Contract: Concepto, ecosistema y principales cuestiones de Derecho privado", en La Ley mercantil, núm. 47, 2018.

FINANTSINSPEKTSIOON, The legal framework of initial coin ofering in Estonia (https://www.fi.ee/index.php?id=22715).

Garcimartín Alférez, F. J., Derecho Internacional Privado, Civitas, $3^{\mathrm{a}}$ ed. 2016

GATES, M., Blockchain. Ultimate guide to understanding blockchain, bitcoin, cryptocurrencies, smart contracts and the future of money, Amazon, 2017.

Gómez De Pomar, F.; GonzÁlez ORTIZ, D., "El contrato de compraventa (6). Los contratos de venta especial de la ley de ordenación del comercio minorista" en YZQUIERDO TOLSADA, M. (Dir.), Contratos - Tomo I. Contratos de finalidad traslativa del dominio (I), $1^{\text {a }}$ ed., Thomson Reuters, Cizur Menor, 2014.

Gómez Orbaneja, E., Derecho Procesal Civil, vol. I, Artes gráficas y ediciones, Madrid, 1976.

GonZÁLEZ-MENESES, M., "Smart contracts: ¿hacia una economía sin derecho contractual?”, en Aranzadi digital, núm. 1/2020.

Gordo Villanueva, M., "Smart contracts y la tecnología blockchain en el derecho contractual”, en Revista Digital Nuevas Tecnologías, n. ${ }^{\circ}$ 12, diciembre, 2017.

GÓRRIZ LÓPEZ, C., "Tecnología blockchain y contratos inteligentes", en NAVAS NAVARRO, S. (Dir.), Inteligencia artificial, Tirant lo blanch, Valencia, 2018.

Holmes, O. W., "The path of the law" en 10 Harvard Law Review, 457, 1897.

Lauslahti, K.; Mattila, J.; Seppälä, T.; "Smart contracts - How will Blockchain technology affect contractual practices?", en ETLA Raportis, núm. 68, 9.1.2017. 
Legerén-Molina, A., "Los contratos inteligentes en España (La disciplina de los smart contracts)", en Revista de Derecho Civil, Vol. 5 N. ${ }^{\circ}$ 2, 2018, págs. 193-241.

LELART, M., El sistema monetario internacional, Acento editorial, Madrid, 1996 (disponible en acceso abierto en: http://www.ehu.eus/ Jarriola/Docencia/SMFI/Michel\%20Lelart_El\%20FMI.pdf).

Lessig, L., Código 2.0, Traficantes de sueños, Madrid, 2006.

Malo Valenzuela, M.A., Remedios frente al incumplimiento contractual. Derecho español, Derecho inglés y Draft Common Frame of Reference, Thomson Reuters, Cizur Menor, 2016, págs.52-55.

Marco Alcalá, L.A., "Contratación al consumo mediante la técnica de vending", en BERCOVITZ RODRÍGUEZ-CANO, A. (Dir.), Contratos mercantiles, $5^{\mathrm{a}}$ ed., THOMSON REUTERS, Cizur Menor, 2012.

Martínez De Aguirre Aldaz, C., Curso de Derecho civil II. Volumen I. Teoría general de la obligación u el contrato, 5. ${ }^{\text {a }}$ ed. Edisofer, Madrid, 2018.

MICROSOFT PATTERNS \& PRACTICES TEAM, Microsoft application architecture guide, Microsoft, 2. ${ }^{\mathrm{a}}$ ed., 2009.

Montero Aroca, J., Gómez Colomer, J.L., Barona Vilar, S., Calderón Cuadrado, M.P., Derecho jurisdiccional II. Proceso civil, 23. ${ }^{a}$ ed., Tirant lo blanch, Valencia, 2015.

Moreno Navarrete, M.A., en La prueba documental. Estudio Histórico-Jurídico y Dogmático, Marcial Pons Barcelona, 2001.g

Orduña Moreno, F.J. y Martínez Velencoso, L.M., La moderna configuración de la cláusula rebus sic stantibus, Thomson Reuters, Cizur Menor, 2013.

Palazón Garrido, M.L., Los remedios frente al incumplimiento en el Derecho comparado, Thomson Reuters, Cizur Menor, 2014.

PARRA LuCÁN, M.A., "La formación del contrato como proceso", en PARRA LUCÁN, M.A. (Dir.), Negociación y perfección de los contratos, Thomson Reuters, Cizur Menor, 2014.

Picó I Junoy, J.; ABel Lluch, X., La prueba documental, J.M. Bosch Editor, Barcelona, 2010, págs. 41-44.

Pino Díez, R; Gómez Gómez, A.; Abajo Martínez, N., Introducción a la inteligencia artificial: sistemas expertos, redes neuronales artificiales y computación evolutiva, Universidad de Oviedo: servicio de publicaciones, 2001. 
Piñar Mañas, J.L. Y Beltrán Sánchez, E. (Dirs.), Comentarios a la Ley de ordenación del comercio minorista y a la Ley Orgánica complementaria, Civitas, Madrid, 1997.

PREnAfETA Rodríguez, J., "Smart contracts: aproximación al concepto y problemática legal básica", en Diario La Ley, núm. 8824, 15.11.2016 (LA LEY 6489/2016).

Preukschat, A., "Capítulo I. Los fundamentos de la tecnología blockchain", en PREUKSCHAT, A. (Coord.), Blockchain: la revolución industrial de Internet, Gestión2000, Madrid, 6ª ed., 2017.

Ramos Simón, L.F., "La gestión de derechos de autor en entornos digitales, un reto para las bibliotecas y centros públicos de información”, en Revista General de Información y Documentación, Vol. 12, núm. 1, 2002 (https://revistas.ucm.es/index.php/RGID/article/viewFile/RGID0202120247A/10205).

RASKIN, M., "The law and legality of Smart contracts" en Georgetown Law Technology Review, 304, 2017.

REITWIESSNER, C., "Solidity" en https://solidity-es.readthedocs.io/es/ latest/introduction-to-smart-contracts.html.

Reglero Campos, L.F. y Busto Lago, J.M., Tratado de responsabilidad civil, 5. ${ }^{\mathrm{a}}$ ed., Thomson Reuters, Pamplona, 2014.

Ríos LóPEz, Y., "La tutela del consumidor en la 'contratación inteligente'. Los 'smart contracts' y la 'blockchain' como paradigma de la Cuarta Revolución industrial” en Revista Consumo y Empresa, n. ${ }^{\circ}$, enero 2019.

SAlvador Coderch, P., "Alteración de circunstancias en el art. 1213 de la Propuesta de Modernización del Código Civil en materia de Obligaciones y Contratos", en InDret, 4/2009.

Salvador Coderch, P., "Contratos inteligentes y Derecho de contratos", en InDret, 3/2018.

SÁnCHEz LoREnzo, S., El derecho inglés y los contratos internacionales, Tirant lo Blanch, Valencia, 2013, pág. 27.

SÁnchez LoREnzo, S., Abogacía internacional (vol. III: Contratos), Rascher, Madrid, 2016.

SÁNCHEZ LoRENZo, S., "Contrato interno e internacional: claves de la diferencia" en HORNERO MÉNDEZ, C. (Dir.), Derecho de contratos: nuevos escenarios y nuevas propuestas, Thomson Reuters Aranzadi, Cizur Menor, 2016. 
Schulze, R. (ed.), Common European Sales Law (CESL). Commentary, C.H. Beck, München, 2012.

SchWAB, K., La cuarta revolución industrial, Debate, 2016.

SzaBo, N., Smart Contracts: Building Blocks for Digital Markets, 1996 (disponible en: http://www.fon.hum.uva.nl/rob/Courses/InformationInSpeech/CDROM/Literature/LOTwinterschool2006/szabo. best.vwh.net/smart_contracts_2.html).

SzaBo, N., The Idea of Smart Contracts, 1997 (disponible en: http:// www.fon.hum.uva.nl/rob/Courses/InformationInSpeech/CDROM/ Literature/LOTwinterschool2006/szabo.best.vwh.net/idea.html).

Szabo, N., A formal language for analyzing contracts, 2002 (http:// www.fon.hum.uva.nl/rob/Courses/InformationInSpeech/CDROM/ Literature/LOTwinterschool2006/szabo.best.vwh.net/contractlanguage.html).

THE LAW LIBRARY OF CONGRESS, Regulation of Cryptocurrency Around the World, junio 2018 (disponible en: https://www.loc.gov/ law/help/cryptocurrency/world-survey.php).

Tur Faúndez, C., Smart contracts. Análisis jurídico, Reus, Madrid 2018.

VAQUero LÓPEZ, C., "Autonomía de la voluntad y normas imperativas", en SÁNCHEZ LORENZO, S. (edit.), Derecho contractual comparado. Una perspectiva europea y transnacional. Tomo II, 3 . $^{\mathrm{a}}$ ed., Thomson Reuters, Cizur Menor, 2016, pág. 95.

WERBACH, K; CORNELl, N., "Contracts ex machina", en Duke Law Journal, núm. 67, marzo 2017 (https://scholarship.law.duke.edu/cgi/ viewcontent.cgi? article $=3913 \&$ context $=$ dlj).

Wright, A.; De FILIPI, P., "Decentralized blockchain technology and the rise of Lex cryptographia”, en Social Sciences Research Network, 12.3.2015.

Yanguas Gómez, R., Contratos de conexión a internet, "hosting» y búsqueda: servicios de intermediación en red con consumidores, Aranzadi, Cizur Menor, 2012.

Zarzuelo, J.m. (Coord.), "Estado del arte del internet de las cosas (IoT)", en LÁZARO, F., Estado del arte e implicaciones de seguridad y privacidad en el Internet de las Cosas, CEM, ISMS Forum Spain, 17.10.2017. 


\section{Blogs/periódicos digitales:}

ARTIFICIAL LAWYER, "HSF + IBM Build Australian National Blockchain for Smart Contracts", en Artificial Lawer (https://www.artificiallawyer.com/2018/08/29/hsf-ibm-build-australian-national-blockchain-for-smart-contracts/).

Blanco Moro, V., "El internet de la información ya es el del valor", en ElEconomista.es, 18.4.2018 (http://www.eleconomista.es/mercados-cotizaciones/noticias/9081475/04/18/El-Internet-de-la-informacion-ya-es-el-del-valor.html).

Blanco Pérez, M. A.; López Román, E.; Montalván Calderón, E.; SuÁrez Otero, E.; Farran Castellà, P; Espinoza Valencia, F., "Contratos inteligentes: los "smart contract", en Blog ENATIC, Consejo General de la Abogacía Española, 6.3.2017 (https://www.abogacia. es/2017/03/06/contratos-inteligentes-los-smart-contract/).

BucK, J., "Oráculos de Blockchain explicados", en Cointelegraph, 18.10.2017 (https://es.cointelegraph.com/explained/blockchainoracles-explained).

Carrascosa Cobos, C., "Qué es un token y para qué sirve", en https:// www.bbva.com/es/que-es-un-token-y-para-que-sirve/.

CCN, "Andy Warhol's Multi-Million Dollar Painting Tokenized and Sold on Blockchain" en https://www.ccn.com/andy-warhols-multimillion-dollar-painting-tokenized-and-sold-on-blockchain/.

Colombo, C., “¿Un mundo sin abogados? Siglo XXI: smart contracts”, LinkedIn, 2017 (https://es.linkedin.com/pulse/un-mundo-sin-abogados-siglo-xxi-smart-contracts-camila-colombo).

Euler, T., "The Token Classification Framework: A multi-dimensional tool for understanding and classifying crypto tokens" en http://www. untitled-inc.com/the-token-classification-framework-a-multi-dimensional-tool-for-understanding-and-classifying-crypto-tokens/.

FISCALIDADBTC, "El regulador vs la realidad en la valoración FIFO de los medios de cambio" en https://medium.com/@fiscalidadbtc/ el-regulador-vs-la-realidad-en-la-valoraci\%C3\%B3n-fifo-de-losmedios-de-cambio-597e959bc91b.

FISCALIDADBTC, "Los contratos inteligentes y el Derecho", en https://medium.com/@fiscalidadbtc/los-contratos-inteligentes-y-elderecho-c5ef82b1641.

Herrera, C., “¿Qué son los stablecoins o monedas estables?”, en https:// www.coincrispy.com/2018/05/26/stablecoins-monedas-estables/. 
Landulce, E., "Entrevista a Martin Hilbert. El gurú del "Big Data": Facebook sabe más de ti con 250 likes que tú mismo", El Mundo (http://www.elmundo.es/papel/futuro/2017/11/27/5a1ab61322601d d03b8b4603.html).

López Morales, T., "Por qué deberías entender cuanto antes qué es la 'token-economía”, en RETINA EL PAÍS (https://retina.elpais.com/ retina/2018/06/06/tendencias/1528290622_215428.html).

MIT Technology Review, "La receta del caos: regular los contratos inteligentes sin saber qué son", en https://www.technologyreview. es/s/10117/la-receta-del-caos-regular-los-contratos-inteligentes-sinsaber-que-son.

Mora Astaburuaga, A., “¿Para qué sirven los Contratos Inteligentes? Smart contracts como herramienta de cambio", en Legal Today, 16.1.2020.

MorA, A., "Las ICOs no están reguladas... ¿O sí? Análisis jurídico de la token-economía”, en TicsLaw, 13.10.2018 (http://ticslaw.es/las-icosno-estan-reguladas-o-si-analisis-juridico-de-la-token-economia/).

Mora, A., "Monedas virtuales ¿Hasta dónde llega el concepto?”, en TicsLaw (http://ticslaw.es/monedas-virtuales/).

Morell Ramos, J., "Cómo crear un smart contract mediante términos y condiciones", en https://terminosycondiciones.es/2016/09/21/como-crear-smart-contract-mediante-terminos-condiciones/.

NaKamoto, S., "Bitcoin: un sistema de efectivo electrónico usuario-ausuario", en https://bitcoin.org/files/bitcoin-paper/bitcoin_es_latam.pdf.

Nieto, A., “¿Qué es una ICO? La tecnología que está revolucionando la financiación empresarial”, en XATAKA ( $v i d$. https://www.xataka. com/empresas-y-economia/que-es-una-ico-la-tecnologia-que-estarevolucionando-la-financiacion-empresarial).

OROYFINANZAS, “¿Qué son los contratos inteligentes o smart contracts? Bitcoin y Ethereum o el dinero programable", en https:// www.oroyfinanzas.com/2015/11/que-son-contratos-inteligentessmart-contracts/.

OROYFINANZAS, "El Internet del futuro es la Blockchain del Internet del Valor", en https://www.oroyfinanzas.com/2017/01/internetfuturo-blockchain-internet-valor/. 
Ortega, A.; Puertas, O., "Blockchain, admitido como medio de prueba en juicio en China”, en Blog Quatrecasas (https://blog.cuatrecasas. com/propiedad-intelectual/blockchain-prueba-juicio-china/).

Pascual, M. G., "Si quieres ser jurista, aprende a programar", Retina. El País, 2018 (https://retina.elpais.com/retina/2018/01/26/tendencias/1516984111_539811.html).

Perasso, V., "Qué es la cuarta revolución industrial (y por qué debería preocuparnos)", BBC Mundo, 2016 (http://www.bbc.com/mundo/ noticias-37631834).

Plaza López, J. A., "Los "smart contracts" no son tan perfectos como nos han vendido", Retina. El País, 2018 (https://retina.elpais.com/ retina/2018/03/05/tendencias/1520249835_156767.html).

Pollock, D., "Volatility: The Necessary Evil Of Cryptocurrency And How To Handle It", en https://cointelegraph.com/news/volatilitythe-necessary-evil-of-cryptocurrency-and-how-to-handle-it.

Prenafeta Rodríguez, J., “¿Debe cumplir la emisión de criptomonedas y tokens la normativa de mercado de valores?" en Blog ENATIC, Consejo General de la Abogacía Española, 21.5.2018 (https:// www.abogacia.es/2018/05/21/debe-cumplir-la-emision-de-criptomonedas-y-tokens-la-normativa-de-mercado-de-valores/)

RAMOs SIMÓN, L.F., "DRM: Protección versus accesibilidad de la información digital”, en hipertext.net, núm. 2, 2004 (https://www.upf. edu/hipertextnet/numero-2/drm.html).

Rosales De Salamanca Rodríguez, F., "Qué es un Smart contract para un notario" en https://www.notariofranciscorosales.com/smartcontract-y-la-maquina-de-pinball/.

SCHNEIER, B., "There's no good reason to trust blockchain technology", en WIRED (https://www.wired.com/story/theres-no-good-reason-to-trust-blockchain-technology/).

STARK, J., "Making sense of Blockchain Smart Contracts", en Coindesk, 2016 (https://www.coindesk.com/making-sense-smart-contracts/).

TICBEAT, “¿Qué es “cloud computing”? Definición y concepto para neófitos", en http://www.ticbeat.com/cloud/que-es-cloud-computing-definicion-concepto-para-neofitos/.

VolPICELLI, G., "Smart contracts sound boring but they're more disruptive than bitcoin", en Motherboard (https://motherboard.vice. com/en_us/article/pgaxjz/smart-contracts-sound-boring-but-theyre-more-disruptive-than-bitcoin). 


\section{Páginas web:}

AGRELLO: https://www.agrello.io/.

ALASTRIA: https://alastria.io/assets/resources/Alastria-Identidad.pdf.

COINSCHEDULE: https://www.coinschedule.com/stats.html.

CREATIVE COMMONS: https://creativecommons.org/ licenses/?lang=es_ES.

ETHEREUM: https://www.ethereum.org/.

FIZZY: https://fizzy.axa/.

CHANGE THE BLOCK: https://www.changetheblock.com/.

HYPERLEDGER: https://www.hyperledger.org/.

INTEROUTE: https://www.interoute.es/what-iaas.

LIBROBLOCKCHAIN: http://libroblockchain.com/blockchain-privada/.

MASTERTHECRYPTO: https://masterthecrypto.com/guide-to-cryptocurrency-wallets/?lang=es.

NEM: https://nem.io/technology/.

OPENBAZAAR: https://www.openbazaar.org/features/.

RIPPLE: https://ripple.com/.

SLOCK.IT: https://slock.it/.

SMARTCONTRACT: https://www.smartcontract.com/.

SOLIDITY: http://solidity.readthedocs.io/en/v0.4.24/.

TRANSLEX: https://www.trans-lex.org/919000/_sanctity-of-contracts/.

WIKIPEDIA: https://es.wikipedia.org/wiki/Insurtech\#cite_note-1. 
